\title{
Effect of Element Diffusion Through Metallic Networks During Oxidation of Type 321 Stainless Steel
}

\author{
Z. Zeng, K. Natesan, Z. Cai, D. Gosztola, R. Cook, and J. Hiller
}

(Submitted December 22, 2013; in revised form January 25, 2014; published online February 20, 2014)

\begin{abstract}
A detailed study was conducted on localized oxidation on Type 321 stainless steel (321ss) using synchrotron $x$-ray nanobeam analysis along with Raman microscopy. The results showed the presence of metallic nanonetworks in the oxide scales, which plays an important role in the continued oxidation of the alloy at $750{ }^{\circ} \mathrm{C}$. A mechanism is proposed to explain the rapid oxidation of $321 \mathrm{ss}$ in complex gaseous environments at elevated temperature. Neutral metal atoms could diffuse outward, and carbon atoms could diffuse inward through the metallic nanonetworks in oxide layers. Alternately, diffusion tunnels can dramatically affect the phase composition of the oxide scales. Since the diffusion rate of neutral metal and carbon atoms through the metallic nanonetworks can be much faster than the diffusion of cations through $\mathrm{Cr}_{2} \mathrm{O}_{3}$, the metallic nanonetwork provides a path through the protective $\mathrm{Cr}_{2} \mathrm{O}_{3}$ layer for the rapid outward diffusion of metallic chromium and iron atoms to the nonprotective spinel layer. This diffusion process affects the solidstate reaction near the alloy-oxide boundary, and a dense $\mathrm{Cr}_{2} \mathrm{O}_{3}$ protective layer does not form. The classic stable structure of the oxide scales, with a dense $\mathrm{Cr}_{2} \mathrm{O}_{3}$ layer at the bottom, is damaged by the rapid diffusion through the tunnel at the reaction front, resulting in locally accelerated oxidation. This process can subsequently lead to "breakaway" oxidation and catastrophic failure of the alloy.
\end{abstract}

Keywords advanced characterization, corrosion testing, electron microscopy

\section{Introduction}

Oxidation and carburization of alloy materials at high temperatures is a long-standing problem that leads to huge economic and energy losses (Ref 1-4). Such degradation retards the improvement of energy conversion efficiency that requires higher operating temperatures in process systems (Ref 1-4). If the efficiency of coal-fired power plants can be improved from the current $\approx 30 \%$ to $50 \%$, then 4.6 billion tons of $\mathrm{CO}_{2}$ emissions could be reduced annually. Meanwhile, 1.6 billion tons of coal and fuel costs of 200 billion dollars would be saved annually. To improve the oxidation resistance of metallic materials at elevated temperatures, it is important to further understand the potential oxidation mechanisms of alloys exposed to high-temperature complex gaseous environments.

In general, alloys are protected from continuous oxidation by the oxide scales that develop on their surface at high temperatures when exposed to complex gaseous environments (Ref 5). Phase composition of the oxide scales dramatically affects the capability of the scales to protect the alloy from oxidation at high temperatures. Typically, $\mathrm{Cr}_{2} \mathrm{O}_{3}$ scales are protective, but spinel is not.

Z. Zeng, K. Natesan, Z. Cai, D. Gosztola, R. Cook, and J. Hiller, Argonne National Laboratory, Argonne, IL 60439. Contact e-mail: zeng@anl.gov.
With advances in surface analysis techniques, it is currently possible to analyze the oxidized surfaces to a much higher resolution in characterizing the phases, compositions, composition gradients, and other factors in alloys that develop reaction layers when exposed to complex gas environments at elevated temperatures. $\mathrm{x}$-ray diffraction (XRD) is the best method to evaluate the composition of phases in the oxide scales, but the sizes of regular x-ray beams means they generally cannot be focused on the oxide scales that are normally fairly thin with the size range on the order of nanometers-to-micrometer scale.

The 2ID-D beamline of the APS at Argonne National Laboratory produces a monochromatic x-ray beam size of $200 \times 300 \mathrm{~nm}$. The advantage of the synchrotron $\mathrm{x}$-ray nanobeam is that the technique can be used to determine both the chemical composition by x-ray fluorescence and phase identification by XRD, within the nanosize area. Our recent study using nanobeam $\mathrm{X}$-ray analysis indicated that the surface scales on alloys could be a mixture of oxides and metallic particles. These metallic nanoparticles can self-assemble into nanonetworks and act as channels for the transportation of certain constituent elements that exhibit high diffusion rates in metals (Ref 6). Although metallic particles have been observed in the oxide scales on alloys after exposure to steam at elevated temperatures since 1970 ( Ref 7,8), the effects of metallic nanonetworks on elemental transport and oxidation have not been evaluated in traditional oxidation/corrosion experiments.

Diffusion of alloy constituents and gas-phase constituents play an important role in the development of the oxide scales and in their microstructural characteristics. Since the proposal of the theory of oxidation by Carl Wagner in 1933 (Ref 5), diffusion of charged species such as cations, anions, and electrons has been considered as the avenue for transport through oxide scales because the scales are usually considered to consist of only oxide phases. However, if there are metallic 
nanonetworks in the oxide scales, then an additional diffusion route emerges since neutral metal atoms like $\mathrm{Cr}$ and $\mathrm{Fe}$ can diffuse outward, and carbon atoms can diffuse inward along the metallic nanonetworks.

In this paper, we present a novel transport route for breakaway oxidation that can lead to catastrophic degradation of metallic components exposed to elevated temperatures.

\section{Experimental Procedures}

\subsection{Oxidation Experiments}

Type 321 stainless steel (321ss) with a composition (in wt.\%) of $\quad 70.35 \mathrm{Fe}-17.3 \mathrm{Cr}-10.3 \mathrm{Ni}-1.2 \mathrm{Mn}-0.4 \mathrm{Si}-0.4 \mathrm{Ti}-0.04 \mathrm{C}-0.01 \mathrm{~N}$ was selected for the experiments. Oxidation experiments were conducted in an experimental system that consists of a horizontal, tubular, high-temperature furnace capable of operating up to $1000{ }^{\circ} \mathrm{C}$. The reaction chamber consisted of a quartz tube (74-cm length, 5-cm OD, 0.32-cm thick), which was centered in a $30-\mathrm{cm}$-diameter resistive heating furnace. Type 316ss flange caps with an O-ring seal were used to close the ends of the quartz tube. The flange caps provided port fittings for the gas flow and steam/vapor preheater. A Barber-Coleman Model 560 three-mode controller was used to control the furnace temperature. A chromel-alumel thermocouple, inserted from one end of the reaction chamber, was used to monitor the specimen temperature. Specimens were suspended from quartz rods held on the top of a high-purity alumina boat. The specimens and the boat were positioned in the constanttemperature section of the reaction chamber. The specimens were exposed to pure $\mathrm{CO}_{2}, 0.1 \% \mathrm{O}_{2}-99.9 \% \mathrm{CO}_{2}, 3.97 \% \mathrm{O}_{2}$ $96.03 \% \mathrm{CO}_{2}$, and $21 \% \mathrm{O}_{2}-79 \% \mathrm{CO}_{2}$ with a gas flow rate of 300 $\mathrm{ml} / \mathrm{min}$ at $750{ }^{\circ} \mathrm{C}$. Specimens were weighed after exposure, and the mass gain was measured to evaluate the oxidation resistance.

\subsection{Characterization of the Oxide Scales}

After exposure at elevated temperatures, the specimens were cut and metallographic mounts were prepared for cross-sectional analysis. The microstructure of each specimen was examined using a Hitachi S4700-II scanning electron microscope (SEM). Nanobeam X-ray analysis was performed at the 2ID-D beamline of the APS at Argonne National Laboratory. The x-ray nanobeam (beam size of $200 \times 300 \mathrm{~nm}$ ) was scanned across the cross sections at both the breakaway and protective regions from the surface to the interior of the alloy specimens (Ref 6). Using a Si(001) doublecrystal monochromator and zone plate optics, the $\mathrm{x}$-ray nanoprobe in the experimental station produced a monochromatic x-ray beam of size of $200 \times 300 \mathrm{~nm}$ and a photon flux of $5 \times 10^{9}$ photons $/ \mathrm{s}$ with an x-ray energy bandwidth $(d E / E)$ of $0.01 \%$. The focal plane of the zone plate optics was adjusted to obtain a minimum spot size at the surface of the specimen. The beam was incident upon the region of interest on the specimen, and scattering intensity in a section of reciprocal space was captured by a flat, two-dimensional detector (CCD camera). Specimens for synchrotron radiation experiments were prepared in a similar manner as those for the cross-sectional analysis in SEM. The beam energy was $8.5 \mathrm{KeV}$ for the XRD experiment. The position of the oxide-metal interface was determined by monitoring the Fe-fluorescence counts as the sample was translated across the beam.

Raman spectra were recorded using a Raman microscope (Renishaw, Inc.) typically using $5 \mathrm{~mW}$ of 514.5-nm excitation,
$10 \mathrm{~s} /$ point, and $2-\mu \mathrm{m}$ steps between map points. The microscope was equipped with a $50 \times 0.75$ na objective (Leica) and a computer controlled X-Y sample stage (Prior), which was used for automated mapping.

Electron energy loss spectra (EELS) and energy-dispersive $\mathrm{X}$-ray spectra (EDX) were acquired with a FEI Tecnai F20ST transmission electron microscope (TEM). The sample for the TEM experiment was cut by a Zeiss $1540 \mathrm{XB}$ focused ion beam (FIB) microscope from a cross section of $321 \mathrm{ss}$ after exposure in pure $\mathrm{CO}_{2}$ at $750{ }^{\circ} \mathrm{C}$.

\section{Results and Discussion}

\subsection{Observation of Metallic Networks in Oxide Layer on Alloy After Breakaway Oxidation}

The cross sections of $321 \mathrm{ss}$ after 24-h exposure in pure $\mathrm{CO}_{2}$, $0.1 \% \mathrm{O}_{2}-99.9 \% \mathrm{CO}_{2}$, and $3.97 \% \mathrm{O}_{2}-96.03 \% \mathrm{CO}_{2}$ at $750{ }^{\circ} \mathrm{C}$ were examined by using a SEM. Although most of the areas on the alloy surface were covered by protective scale, locally enhanced oxidation was observed on the surface of all specimens (Fig. 1). The number of local corrosion points and the corrosion depth decreased with the increasing oxygen partial pressure. Breakaway oxidation was initiated from a localized attack on the surface of $321 \mathrm{ss}$, and subsequently propagated over the entire surface after prolonged exposure. However, such breakaway oxidation did not occur when the stainless steel was exposed to $21 \% \mathrm{O}_{2}-79 \% \mathrm{CO}_{2}$ for $320 \mathrm{~h}$ at the same temperature.

Two oxide layers were observed in the breakaway region. The nanobeam XRD analysis indicates that the outer layer of the breakaway region consists of $\mathrm{Fe}_{3} \mathrm{O}_{4}$, whereas (Mn,Fe)$\mathrm{Cr}_{2} \mathrm{O}_{4}$ spinel is observed at the middle and inner scale regions (Fig. 2a). $\mathrm{Fe}_{2} \mathrm{O}_{3}$ was also observed on some areas of the oxidegas interface. $\mathrm{Cr}_{2} \mathrm{O}_{3}$ and $\mathrm{FeO}$ were not observed in the scales of the breakaway area within the detection limit. In the protective region, $\mathrm{Cr}_{2} \mathrm{O}_{3}$ was the primary phase in the oxide scales near the alloy-oxide boundary, whereas spinel was the primary phase at the oxide scales near the surface. Diffraction peaks from NiFe metal phases were observed in the oxide scales of the protective areas (Fig. 2b). These metallic nanoparticles can form in the thermal growth process of the oxide scales (Ref 6, 9 ). Both ferritic and austenitic phases occur in these Ni-Fe nanoparticles. The intensity of the ferritic diffraction peak at $42.1^{\circ}$ ( $d$-space at $2.03 \AA$ ) is much higher than the austenitic diffraction peak at $41.1^{\circ}$, which indicates that the primary phase in these $\mathrm{Ni}-\mathrm{Fe}$ nanoparticles in the oxide scales is ferritic. In contrast, $321 \mathrm{ss}$ has an austenitic structure with the 111 diffraction peak at $41.1^{\circ}$ ( $d$-space at $2.08 \AA$ ) when an x-ray beam energy of $8.5 \mathrm{keV}$ is applied. The intensity of the diffraction peak at $47.6^{\circ}$ from the austenitic Ni-Fe phase near the surface is higher than that near the alloy-oxide boundary, which indicates an increase in the content of austenitic phase in metallic particles. Part of the metallic phase changes to austenitic structure, which may be due to the decrease in iron content in metallic particles near the surface, because iron is more readily oxidized than nickel at high $p_{\mathrm{O}_{2}}$ near the surface.

Nano-XANES (x-ray absorption near-edge structure) indicate that the chemical shift of $\mathrm{Ni}$ at the oxide scales of the protective area is close to that of Ni metal (Fig. 3a). The nickel particles in the oxide scales of the protective area are in their 

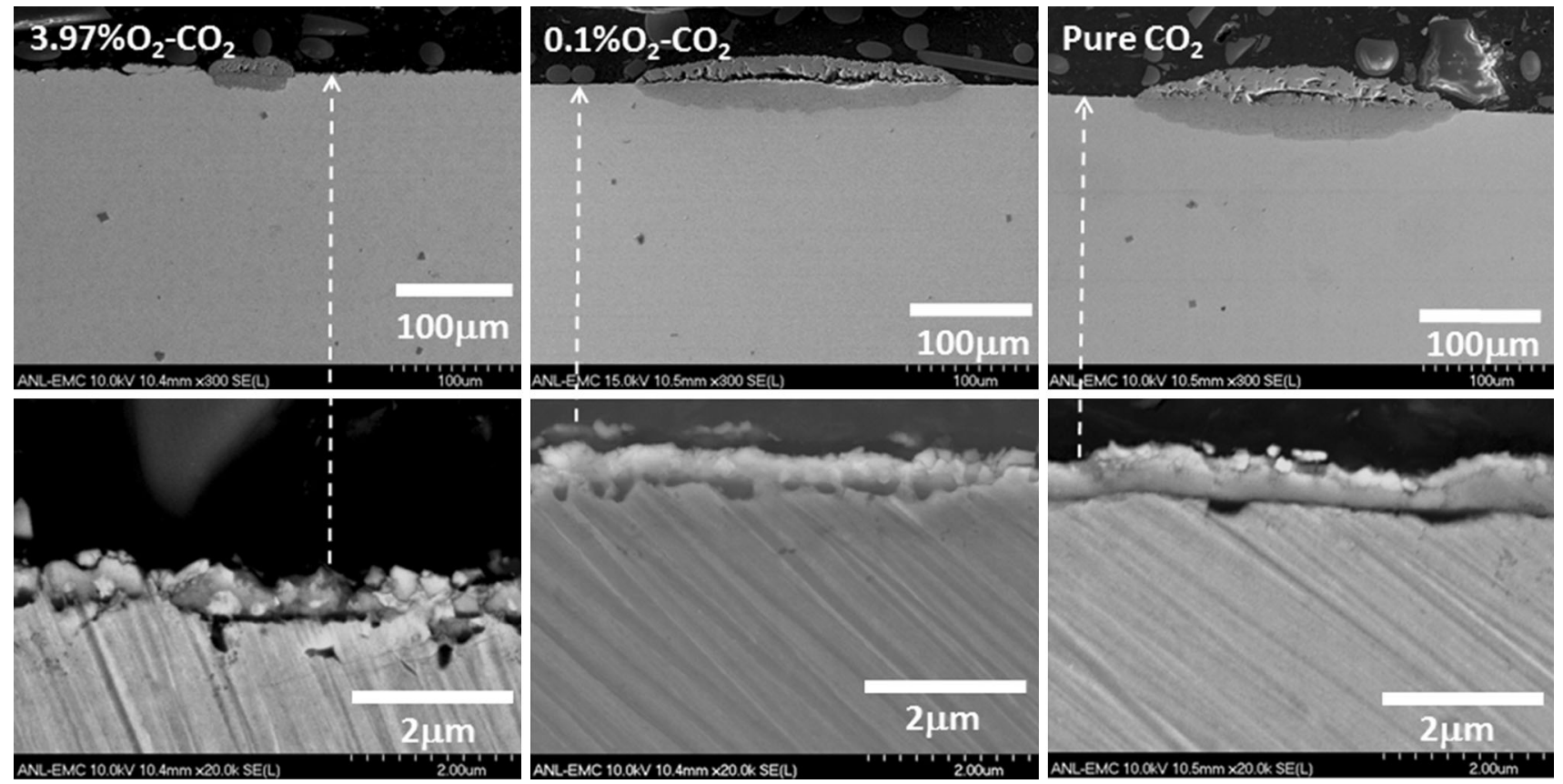

Fig. 1 SEM images of 321 ss upon exposure at $750{ }^{\circ} \mathrm{C}$ for $24 \mathrm{~h}$ to: $3.97 \% \mathrm{O}_{2}-96.03 \% \mathrm{CO}_{2}, 0.1 \% \mathrm{O}_{2}-99.9 \% \mathrm{CO}_{2}$, and pure $\mathrm{CO}_{2}$
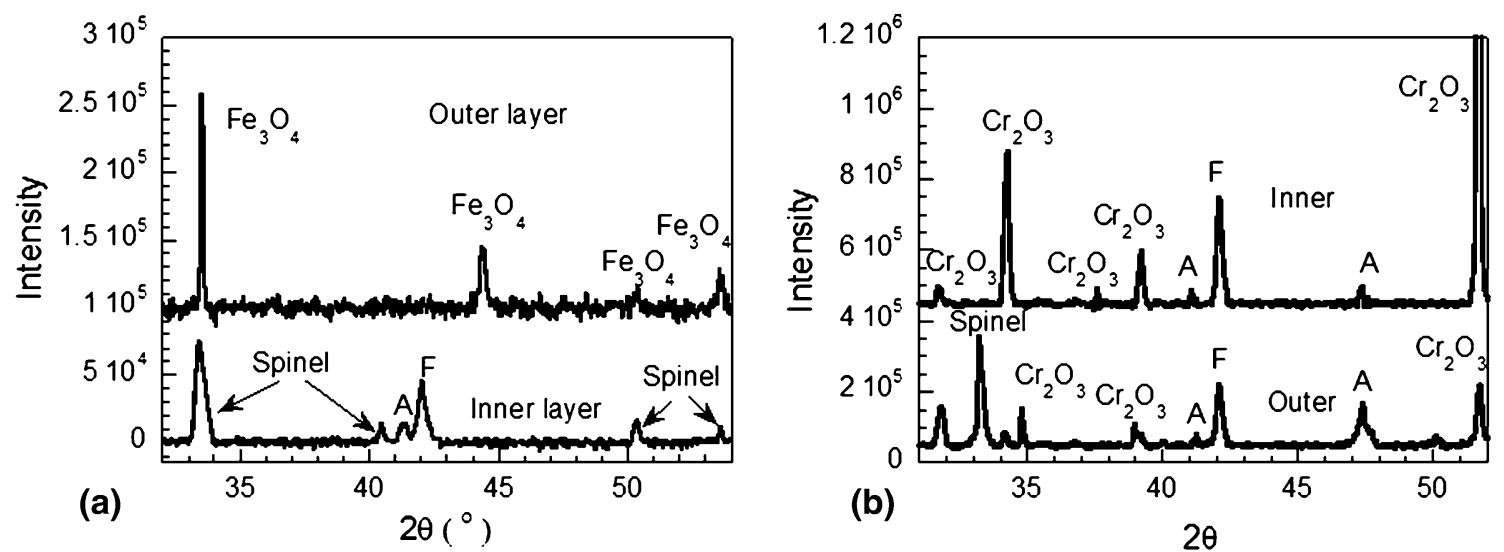

Fig. 2 Synchrotron nanobeam XRD of 321 ss after exposure to pure $\mathrm{CO}_{2}$ at $750{ }^{\circ} \mathrm{C}$ for $284 \mathrm{~h}$ : (a) At the breakaway region; (b) at the protective region. A: austenitic Ni-Fe phase; F: Ferritic Ni-Fe phase

metallic state. Therefore, both nano-XANES and nano-XRD confirm that metallic particles with a primary phase different from the alloy substrate are present in the oxide scales of the protective region. In the breakaway region, the chemical shift of nickel in the inner oxide layer is almost the same as the chemical shift of pure nickel and nickel inside the alloy substrate (Fig 3b), but it is far away from the +2 nickel in the $\mathrm{NiCr}_{2} \mathrm{O}_{4}$ and $\mathrm{NiO}$ standards. Therefore, the primary oxidation state of nickel in the inner oxide layer is determined to be zero. A feature of nanonetworks throughout the inner layer of the nonprotective region was observed (Fig. 4a). SEM shows a two-dimensional network, but both oxide and metallic nanonetworks are probably continuous in three dimensions. Metallic phases were also observed at the inner oxide layer of the breakaway region by nanobeam XRD. The intensity of the ferritic Ni-Fe diffraction is higher than that of the austenitic phase, which indicates that the ferritic Ni-Fe is the primary phase.
These observations indicate that metallic nanoparticles are present in the oxide scales at both the breakaway region and the protective region. The elemental distribution in the oxide scales in the protective region on $321 \mathrm{ss}$ is different from that observed in the breakaway region. The nickel content is low in the oxide scales of the protective area, whereas the nickel content in the inner oxide layer of the breakaway region is higher than that in the alloy (Fig. 5a and b). These metallic nanoparticles in the oxide layer connect to form networks in the breakaway region, but such networks do not form in the oxide scales of the protective region because the nickel meal particle density is not as high as in the oxide layer of the breakaway region.

The pre-edge feature in the K-edge XANES spectra of transition metals is associated with quadrupole transitions from the $1 \mathrm{~s}$ to $3 \mathrm{~d}$ orbital (Ref 10,11 ), and has been shown to increase in strength with the increasing Fe valence (or $d$-hole population). The oxidation state of iron in $\mathrm{Fe}_{3} \mathrm{O}_{4}$ is higher than that in 

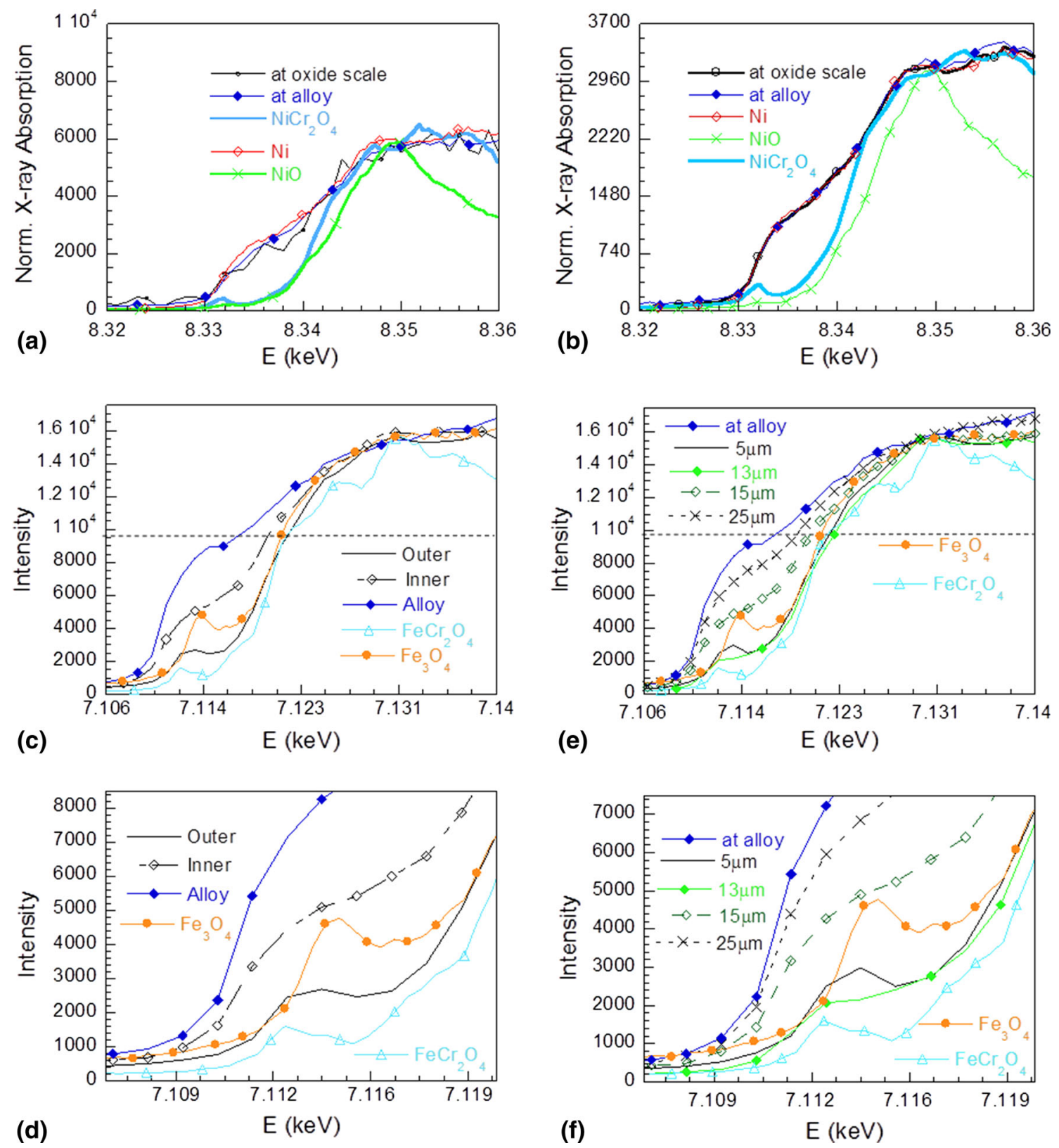

Fig. 3 The normalized absorption coefficients of $\mathrm{K}$ edge of $321 \mathrm{ss}$ after exposure to pure $\mathrm{CO}_{2}$ at $750{ }^{\circ} \mathrm{C}$ for $284 \mathrm{~h}$ : (a) Ni $\mathrm{K}$ edge at the protective region; (b) Ni K edge at the breakaway region; (c) Fe K edges at the outer and inner positions in oxide scale at protective region; (d) Fe pre-K edges at the outer and inner positions in oxide scale at protective region; (e) Fe $\mathrm{K}$ edges at the positions from gas-oxide surface at the breakaway region; (f) Fe pre-K edges at the positions from gas-oxide surface at the breakaway region

$\mathrm{Fe}^{2+} \mathrm{Cr}_{2} \mathrm{O}_{4}$. Therefore, the intensity of the pre-edge in $\mathrm{Fe}_{3} \mathrm{O}_{4}$ is higher than that in $\mathrm{FeCr}_{2} \mathrm{O}_{4}$, and the peak position of the preedge of iron in $\mathrm{Fe}_{3} \mathrm{O}_{4}$ is also shifted to higher energy. The peak position and intensity of the Fe pre-edge at the outer oxide layer ( $5 \mu \mathrm{m}$ from surface) in the breakaway region is between those of $\mathrm{Fe}_{3} \mathrm{O}_{4}$ and $\mathrm{FeCr}_{2} \mathrm{O}_{4}$ (Fig. 3e). Therefore, the $\mathrm{Fe}$ oxidation state at the outer oxide layer is between 2 and 2.66. Near the boundary of outer and inner oxide scales, the intensity of $\mathrm{Fe}$ pre-edge decreases, and the peak position moves to lower energy, which indicates that the oxidation state of iron decreases. Figure 3(f) shows that the chemical shift of Fe systematically moves to lower energy when the scan position moves toward the metal-oxide boundary. The chemical shift of $\mathrm{Fe}$ at the inner oxide layer is at a lower energy than that of the
$\mathrm{Fe}^{2+}$ standard of $\mathrm{FeCr}_{2} \mathrm{O}_{4}$. This indicates that there is a mixture of iron metal and iron oxides in the inner scale layer of the breakaway region. The systematic shift indicates that the metallic iron content increases with the decreasing distance from the alloy-oxide boundary. In the protective region, the oxidation state of iron near the gas side is between 2 and 2.66 , and the metallic iron is also observed near the oxide-metal boundary (Fig. 3c and d). Since metallic nickel was also observed in the oxide layers in both the breakaway and the protective region, the metallic nanoparticles or networks consist of both metallic nickel and iron.

Metallic nanonetworks will be oxidized if the $p_{\mathrm{O}_{2}}$ is too high at location near surface. The above results indicate that the outer layer primarily consists of $\mathrm{Fe}_{3} \mathrm{O}_{4}$, where $p_{\mathrm{O}_{2}}$ is high 

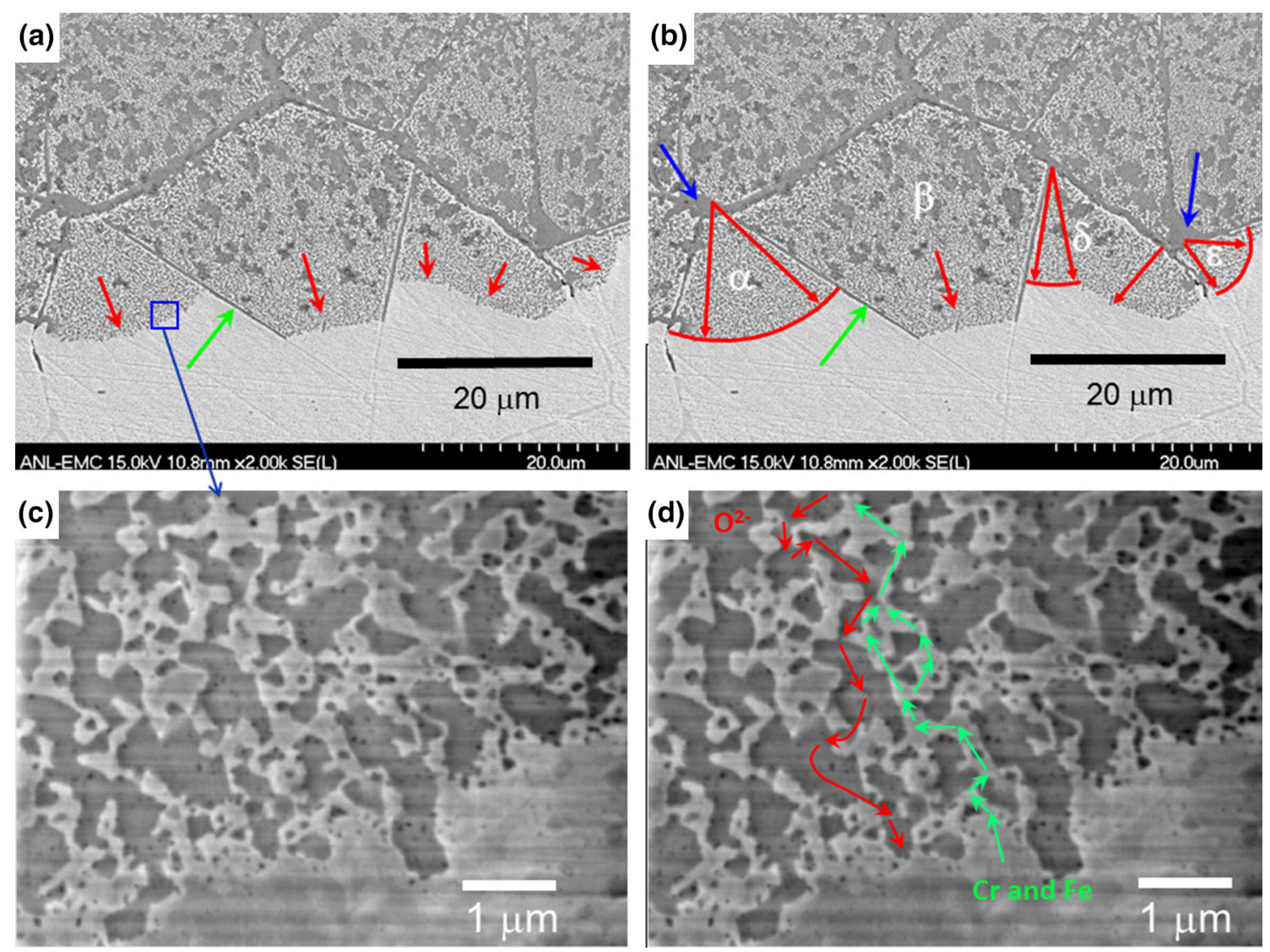

Fig. 4 SEM images of breakaway region of 321ss after 284-h exposure to pure $\mathrm{CO}_{2}$ at $750{ }^{\circ} \mathrm{C}$ : (a) Oxide layer grows out at the localized attack region. Oxidation propagates along the red arrow. The green arrow indicates that the oxidation process cannot propagate across discontinuities in the metallic network across the grain boundary. (b) Oxidation propagates from a point and forms arc lines in grain $\alpha$ and $\varepsilon$. (c) Highmagnification images from the blue square region of a, EDX analysis indicates that there is more nickel and less oxygen in the bright network than in the dark region. (d) Schematic diagram of metallic nanonetworks in an oxide layer. The bright areas are the Ni-Fe metallic nanonetworks that connect to the alloy substrate and the dark area is oxides. Although some locations within the network are discontinuities in the two-dimensional image, the network is considered to be continuous to allow for the outward diffusion of $\mathrm{Cr}$ and iron atoms because the network is three dimensional. The oxides also form a continuous network to allow oxygen inward diffusion. The network is observed in the entire inner oxide layer (Color figure online)

enough to oxidize nickel metal. The inner layer consists of $\mathrm{FeCr}_{2} \mathrm{O}_{4}$ and $\mathrm{Fe}-\mathrm{Ni}$ metallic nanonetworks. The metallic nanonetworks extends to $20 \mu \mathrm{m}$ (a typical metal grain size), and is about $13 \mu \mathrm{m}$ away from surface in the gaseous environment of pure $\mathrm{CO}_{2}$ at $750{ }^{\circ} \mathrm{C}$.

A FIB microscope was used to cut a small specimen from the breakaway region of the same sample for TEM analysis. The sample was oriented in the TEM so that the different phases had differing contrast in the TEM image of the breakaway region (Fig. 6). The diffraction spots for spinel oxide are observed at location A. Electron diffraction is also observed from the metallic phase in the oxide layer. The chemical compositions of these phases were determined by EDX analysis (Table 1). The analysis (ESVision software, standardless analysis) shows that the phase at location A of Fig. 6 contains 56 at. $\%$ oxygen ( 57 at. $\%$ oxygen in spinel). The oxygen content in the other phase at location B of Fig. 6 is small, which indicates that there is a metallic (non-oxide) phase in the oxide layer of the breakaway region. The nickel content in the oxide phase is low, whereas, its content in the metallic phase is about 25 at.\%, which is consistent with the nanoXANES analysis. The $\mathrm{Cr}$ content in the metallic particle dramatically drops to 1.6 from 18.3 at.\% in the alloy substrate (nominal composition, Table 1). Iron is found in both the oxide phase and the metallic phase (72 at.\%). The oxidation state of iron can be determined by electron energy loss spectra (Ref 12). The peak ratio of $\mathrm{Fe}_{\mathrm{L} 3}$ to $\mathrm{Fe}_{\mathrm{L} 2}$ is 3.4 for metallic iron, but the ratio increases to 5.5 for FeO. The EELS at location B is similar than the EELS of the iron at the alloy substrate (Fig. 7). The measured peak ratio of $\mathrm{Fe}_{\mathrm{L} 3}$ to $\mathrm{Fe}_{\mathrm{L} 2}$ is 3.7 , which is close to the ratio at the alloy substrate and that for metallic iron as measured by Leapman et al. (Ref 12). These results confirm that iron is in metallic form at location B.

EDX analysis using SEM indicated that the bright spots in Fig. 4(a) are rich in iron and nickel but contained less oxygen and chromium than those in the dark region. Based on the previous analysis (Ref 6), which has now been confirmed by the present TEM analysis, these bright spots in the SEM image in Fig. 4(a) are Ni-Fe metal particles. The contrast reversal between the SEM and TEM images is due to different imaging methods. It seems that oxidation stops at the grain boundary as indicated by the green arrow on Fig. 4(a). Oxidation cannot directly propagate down if the network is terminated by the grain boundary, whereas the red arrow indicates that oxidation continued if the network is connected to the alloy substrate. Figure 4(b) shows the oxidation at grain $\alpha$ and $\varepsilon$ initiating from 

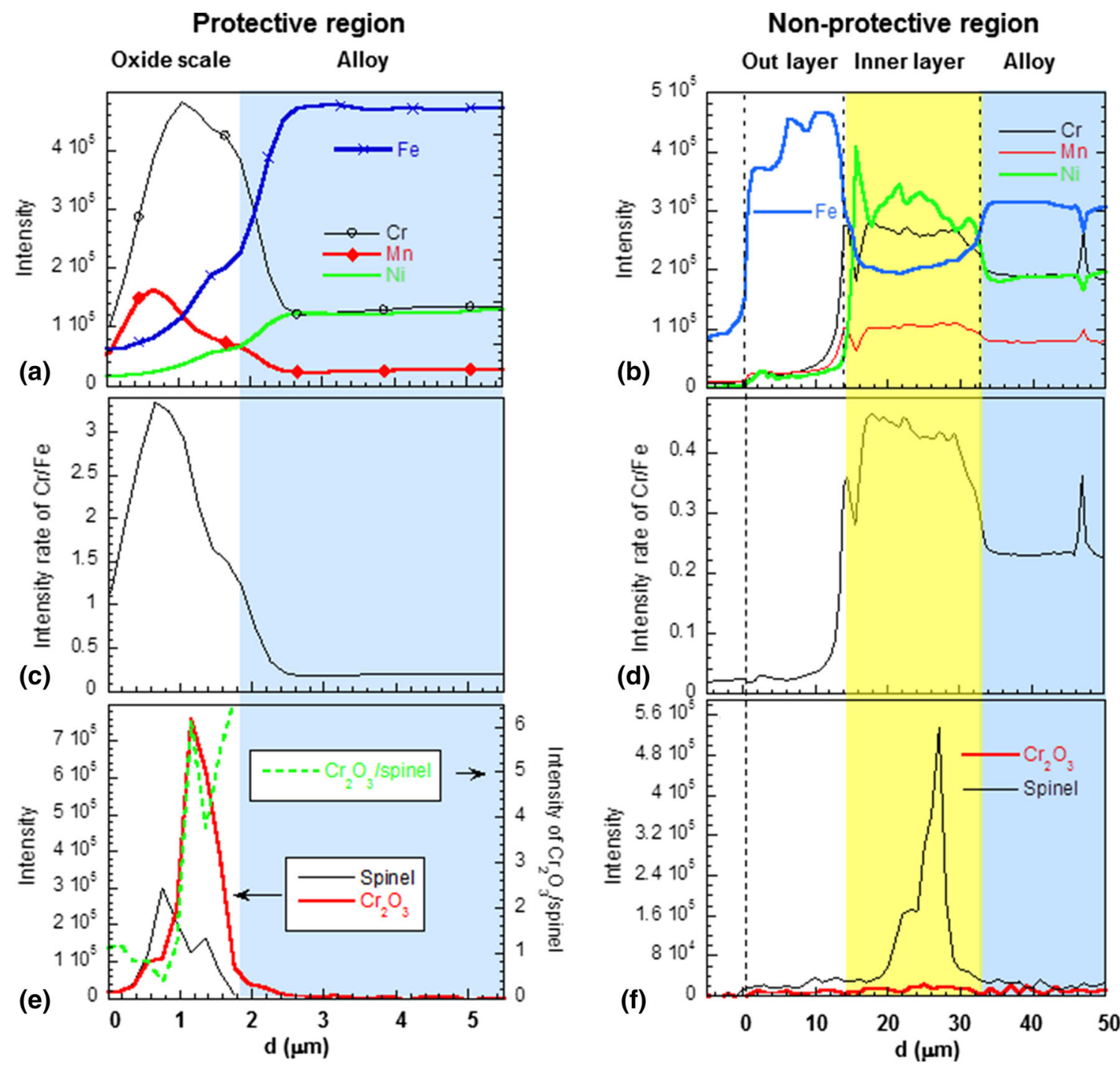

Fig. 5 Nanobeam x-ray fluorescence and diffraction of protective (left) and breakaway (right) regions of 321 ss after exposure to pure $\mathrm{CO}_{2}$ at $750{ }^{\circ} \mathrm{C}$ for $284 \mathrm{~h}$, as a function of scale depth. (a) The nickel concentration in the oxide scale of the protective region is lower than that in the alloy substrate. (b) The nickel concentration in the inner oxide layer of the breakaway region is higher than in the alloy substrate. (c) The relative content of $\mathrm{Cr}$ vs. Fe is high in the oxide scale of protective region. (d) The relative content of $\mathrm{Cr}$ vs. Fe is low in the oxide scale of breakaway region. (e) The relative content of the $\mathrm{Cr}_{2} \mathrm{O}_{3}$ phase vs. spinel phase is high in the protective region. ( $\mathrm{f}$ ) $\mathrm{The}$ relative content of the $\mathrm{Cr}_{2} \mathrm{O}_{3}$ phase vs. spinel phase is low in the breakaway region

a point and propagating with an arc frontline. Although metallic nanoparticles were observed in oxide scale in the protective region, the metallic nanonetworks were only observed in situations where breakaway oxidation occurred. The results indicate that the metallic nanonetworks play an important role in leading to and in continuation of breakaway oxidation. In contrast, no such metallic network feature was observed when $321 \mathrm{ss}$ was oxidized in $21 \% \mathrm{O}_{2}-79 \% \mathrm{CO}_{2}$ at $750{ }^{\circ} \mathrm{C}$ for $200 \mathrm{~h}$. Therefore, metallic nanonetworks are easy to form in the low $p_{\mathrm{O}_{2}}$ environment.

\subsection{Stabilities of Spinel and $\mathrm{Cr}_{2} \mathrm{O}_{3}$}

The relative amount of $\mathrm{Cr}$ in the oxide scales is much higher than that in the alloy, and it forms a sharp peak in the oxide scales of the protective region (Fig. 5c). In contrast, $\mathrm{Cr}$ distributes uniformly in most of the inner oxide layer in the breakaway region, and the concentration ratio of $\mathrm{Cr} / \mathrm{Fe}$ is much lower (Fig. 5d). This ratio affects the phase composition in the oxide scales because the formation of the spinel needs both iron and chromium. In the protective region, both spinel and $\mathrm{Cr}_{2} \mathrm{O}_{3}$ are observed. The content of spinel is high in the outer layer, but it is low in the inner layer of the oxide scales of the protective region (Fig. 5e). In contrast, only spinel is observed in the inner oxide layer of the breakaway region (Fig. 5f). Micro-Raman mapping also confirms a similar phase distribution pattern (Fig. 8). Raman spectra were collected using a $50 \times$ microscope objective with a 5-mW, 514.5-nm laser excitation. The Raman shift at 553 corresponds to $\mathrm{Cr}_{2} \mathrm{O}_{3}$, and the Raman shift at $\sim 680$ corresponds to spinel (Ref 13, 14). The breakaway area of $321 \mathrm{ss}$ consists of spinel only and shows the complete absence of $\mathrm{Cr}_{2} \mathrm{O}_{3}$. However, both $\mathrm{Cr}_{2} \mathrm{O}_{3}$ and spinel were observed in the protective region, with spinel in the outer layer and $\mathrm{Cr}_{2} \mathrm{O}_{3}$ in the inner.

In general, $\mathrm{Cr}_{2} \mathrm{O}_{3}$ is thermodynamically more stable than $\mathrm{FeCr}_{2} \mathrm{O}_{4}$ spinel. The question is why a highly stable $\mathrm{Cr}_{2} \mathrm{O}_{3}$ 

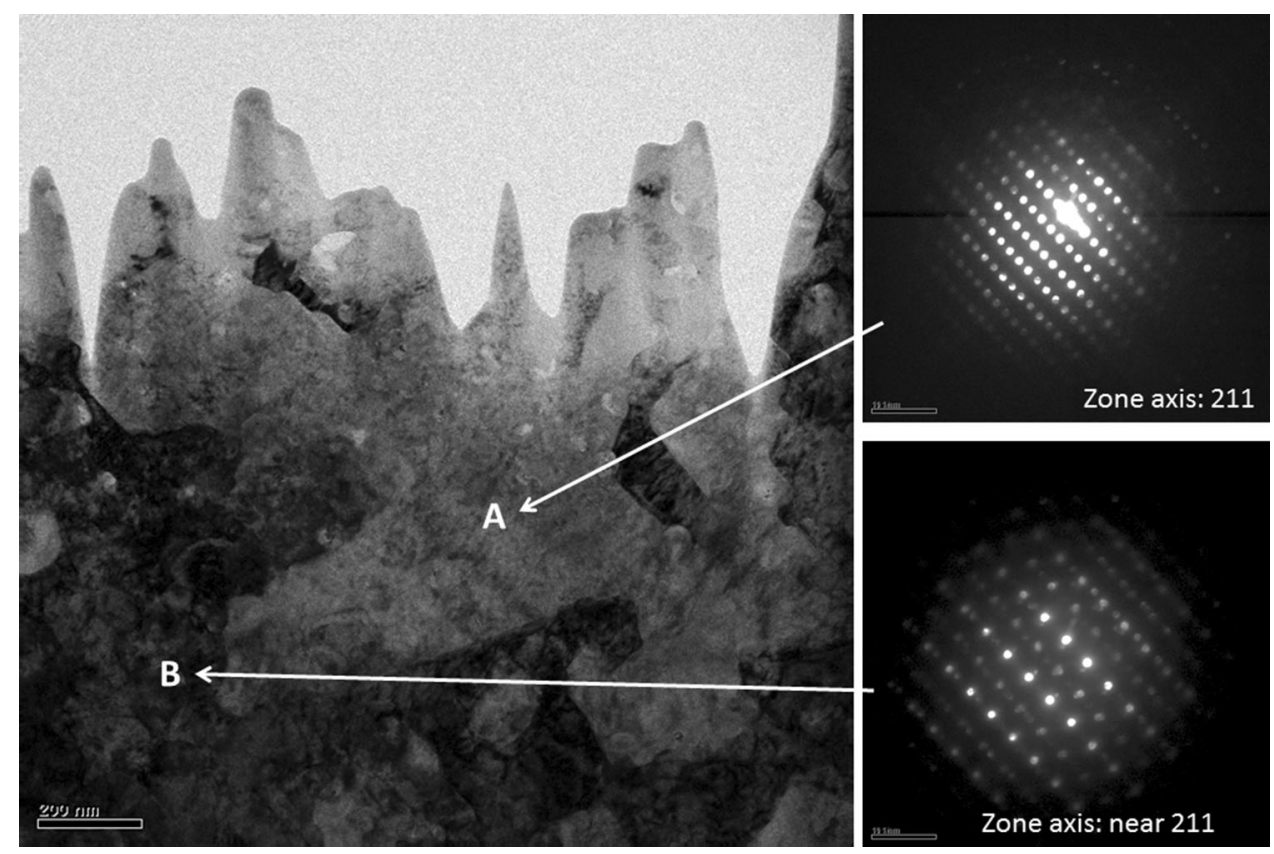

Fig. 6 Left: TEM image (diffraction contrast) at the oxide layer near the alloy substrate in the breakaway region of 321ss after 284-h exposure to pure $\mathrm{CO}_{2}$ at $750{ }^{\circ} \mathrm{C}$. Right: the electron diffraction patterns from oxide and metal were taken at locations $\mathrm{A}$ and $\mathrm{B}$, respectively. Both the oxide and metal are cubic with lattice parameter of 8.35 and $3.51 \AA$, respectively

Table 1 EDX analysis results of the metallic network and oxide layer in Fig. 6

\begin{tabular}{lcc}
\hline Elements & $\begin{array}{c}\text { Concentration in } \\
\text { oxide layer (at.\%) }\end{array}$ & $\begin{array}{c}\text { Concentration in } \\
\text { metallic network (at.\%) }\end{array}$ \\
\hline $\mathrm{Cr}$ & 27.4 & 1.6 \\
$\mathrm{O}$ & 55.9 & See caption \\
$\mathrm{Fe}$ & 13.1 & 71.7 \\
$\mathrm{Ni}$ & 0.2 & 25.3 \\
$\mathrm{Mn}$ & 1.8 & 0.4 \\
Other & 1.6 & 0.9
\end{tabular}

The carbon $\mathrm{K}_{\alpha}$ signal was ignored in both cases. The small oxygen $\mathrm{K}_{\alpha}$ signal from metallic network $(<8$ at.\%) was ignored in the analysis because it was assumed to have originated from post-preparation surface oxidation of the TEM specimen

layer does not exist near the oxide-metal boundary interface. Hansson et al. attribute the primary reason for this phenomenon to the low contact energy between the oxide grain and the metal grain(Ref 15). However, we believe the chemical equilibrium can be affected by the activity of $\mathrm{Cr}$ in the metallic phase in the metallic phase.

The standard change of reaction in Gibbs free energy $\left(\Delta G^{\circ}\right)$ for the following three competitive reactions were obtained from references $(\operatorname{Ref} 16,17)$.

$$
\begin{gathered}
2 \mathrm{Cr}(\mathrm{s})+3 / 2 \mathrm{O}_{2}(\mathrm{~g})=\mathrm{Cr}_{2} \mathrm{O}_{3}(\mathrm{~g}) \\
\Delta G_{1}^{\circ}\left(750^{\circ} \mathrm{C}\right)=-870.0 \mathrm{~kJ} \mathrm{~mol}^{-1} \\
2 \mathrm{Cr}(\mathrm{s})+\mathrm{Fe}(\mathrm{s})+2 \mathrm{O}_{2}(\mathrm{~g})=\mathrm{FeCr}_{2} \mathrm{O}_{4}(\mathrm{~s}) \\
\Delta G_{2}^{\circ}\left(750^{\circ} \mathrm{C}\right)=-1104.3 \mathrm{~kJ} \mathrm{~mol}^{-1}
\end{gathered}
$$

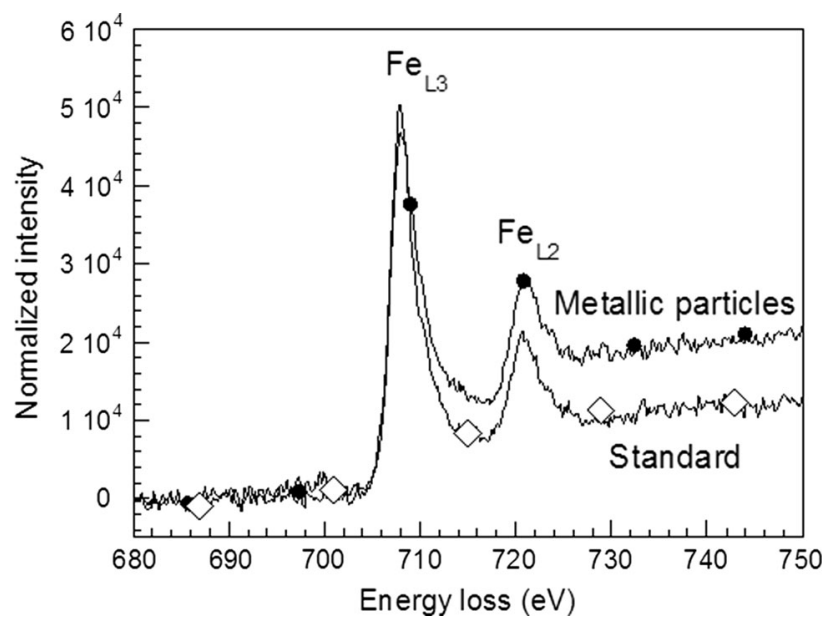

Fig. 7 The electron energy loss spectra that are taken at the metallic particle in oxide layer and at the alloy substrate (used as an iron "standard")

$$
\begin{aligned}
2 \mathrm{Cr}(\mathrm{s})+\mathrm{Ni}(\mathrm{s})+2 \mathrm{O}_{2}(\mathrm{~g}) & =\mathrm{NiCr}_{2} \mathrm{O}_{4}(\mathrm{~s}) \\
\Delta G_{3}^{\circ}\left(750^{\circ} \mathrm{C}\right) & =-1039.6 \mathrm{~kJ} \mathrm{~mol}^{-1}
\end{aligned}
$$

At the equilibrium, the equilibrium constant $(K)$ for each reaction can be calculated from the following equation:

$\ln (K)=-\frac{\Delta G^{\circ}}{R T}$,

where $R$ is the gas constant, and $T$ is the absolute temperature. 

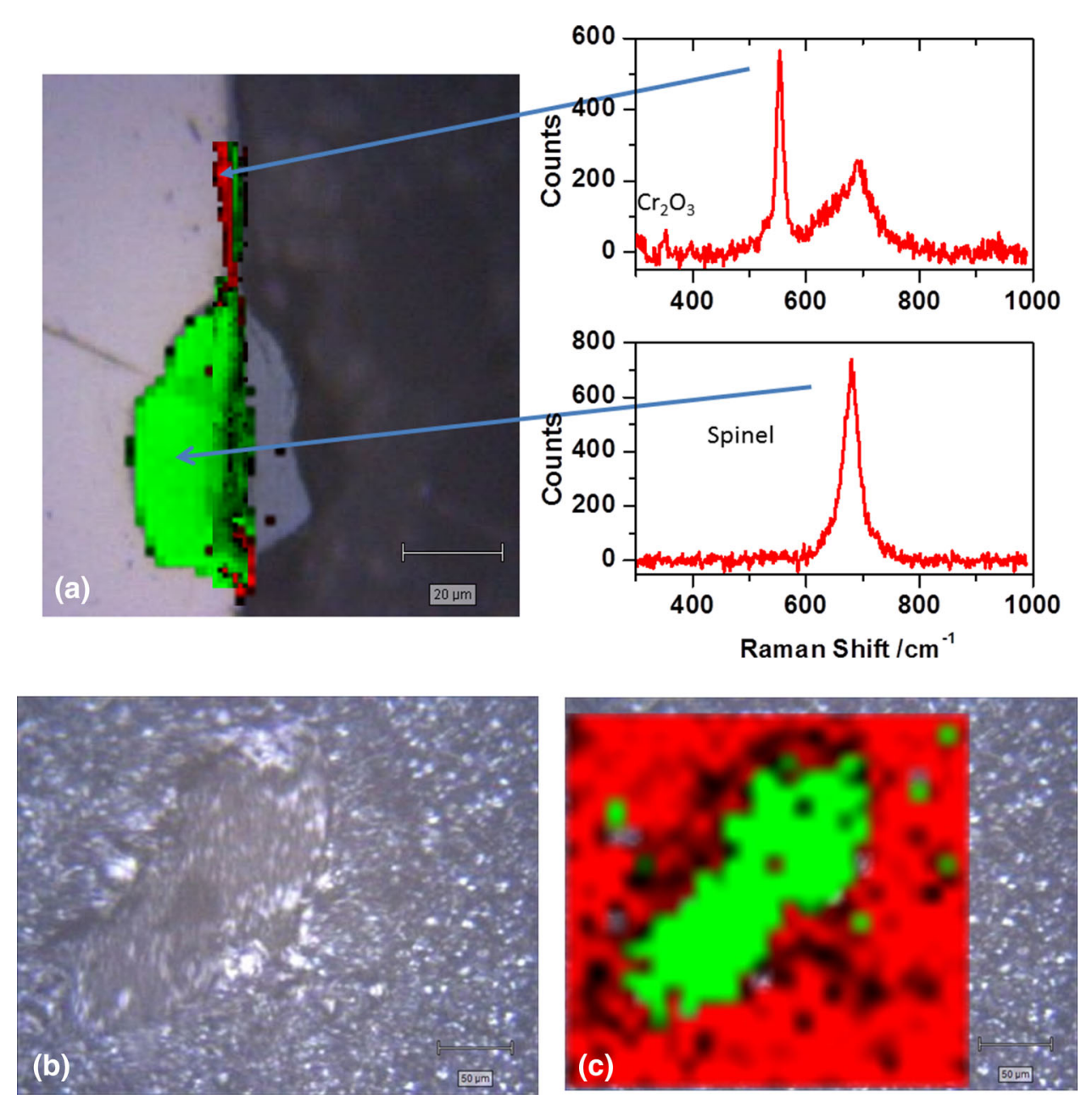

Fig. 8 (a) Micro-Raman area map of a cross section of $321 \mathrm{ss}$ following 284-hour exposure to pure $\mathrm{CO}_{2}$ at $750{ }^{\circ} \mathrm{C}$. Red areas are primarily $\mathrm{Cr}_{2} \mathrm{O}_{3}$, green is primarily spinel. (b) Optical image of the surface of $321 \mathrm{ss}$ following 24-hour exposure to pure $\mathrm{CO}_{2}$ at $750{ }^{\circ} \mathrm{C}$. (c) Micro-Raman area map of (b). Degraded spot consists of spinel (Color figure online)

In a nanomixture system, if we assume that the chemical activity of chromium $\left(a_{\mathrm{Cr}}\right)$ in alloy equals the mole fraction of chromium in the alloy, then the equilibrium constant can be written as

$$
\text { For reaction 1, } K_{1}=\frac{a_{\mathrm{Cr} 2 \mathrm{O} 3}}{a_{\mathrm{Cr}}^{2} a_{\mathrm{O}_{2}}^{3 / 2}}
$$$$
\log a_{\mathrm{O}_{2}}=\frac{2\left(\log a_{\mathrm{Cr}_{2} \mathrm{O}_{3}}-2 \log a_{\mathrm{Cr}}-\log K_{1}\right)}{3}
$$

For reaction 2, $K_{2}=\frac{a_{\mathrm{FeCr}_{2} \mathrm{O}_{4}}}{a_{\mathrm{Cr}}^{2} a_{\mathrm{Fe}} a_{\mathrm{O}_{2}}^{2}}$

$$
\log a_{\mathrm{O}_{2}}=\frac{\log a_{\mathrm{FeCr}_{2} \mathrm{O}_{4}}-2 \log a_{\mathrm{Cr}}-\log a_{\mathrm{Fe} 2}-\log K 2}{2}
$$

For reaction 3, $K_{3}=\frac{a_{\mathrm{NiCr}_{2} \mathrm{O}_{4}}}{a_{\mathrm{Cr}}^{2} a_{\mathrm{Ni}} a_{\mathrm{O}_{2}}^{2}}$

$$
\log a_{\mathrm{O}_{2}}=\frac{\log a_{\mathrm{NiCr}_{2} \mathrm{O}_{4}}-2 \log a_{\mathrm{Cr}}-\log a_{\mathrm{Ni}}-\log K_{3}}{2}
$$

If we assume the chemical activities of $\mathrm{Cr}_{2} \mathrm{O}_{3}, \mathrm{FeCr}_{2} \mathrm{O}_{4}$, and $\mathrm{NiCr}_{2} \mathrm{O}_{4}$ as 1, then Eq 5, 6, and 7 become
For reaction $1, \log a_{\mathrm{O}_{2}}=\frac{2\left(-2 \log a_{\mathrm{Cr}}-\log K_{1}\right)}{3}$

For reaction 2, $\log a_{\mathrm{O}_{2}}=\frac{-2 \log a_{\mathrm{Cr}}-\log a_{\mathrm{Fe}}-\log K_{2}}{2}$

For reaction $3, \log a_{\mathrm{O}_{2}}=\frac{-2 \log a_{\mathrm{Cr}}-\log a_{\mathrm{Ni}}-\log K_{3}}{2}$

The thermochemical calculation results are shown in Fig. 9(a), with the assumption that the activity of iron in the scale as 0.72 and that of nickel in the scales as 0.25 .

In the protective region where the metallic networks are absent, $\mathrm{Cr}_{2} \mathrm{O}_{3}$ is the stable phase on the oxide-metal boundary interface for 321 ss (which contains $17.4 \mathrm{wt} . \% \mathrm{Cr}$ ). A protective layer of $\mathrm{Cr}_{2} \mathrm{O}_{3}$ can form after $\mathrm{Cr}$ is oxidized and accumulate near the oxide-metal boundary. However, when the metallic networks exist, $\mathrm{Cr}$ can diffuse through the nickel-iron metallic network because the diffusion rate of $\mathrm{Cr}$ in metal is higher than its diffusion rate in oxides (Ref 18, 19). In the breakaway region, metallic networks become channels for $\mathrm{Cr}$ transport. Some of the $\mathrm{Cr}$ can be consumed by oxidation during transport, 

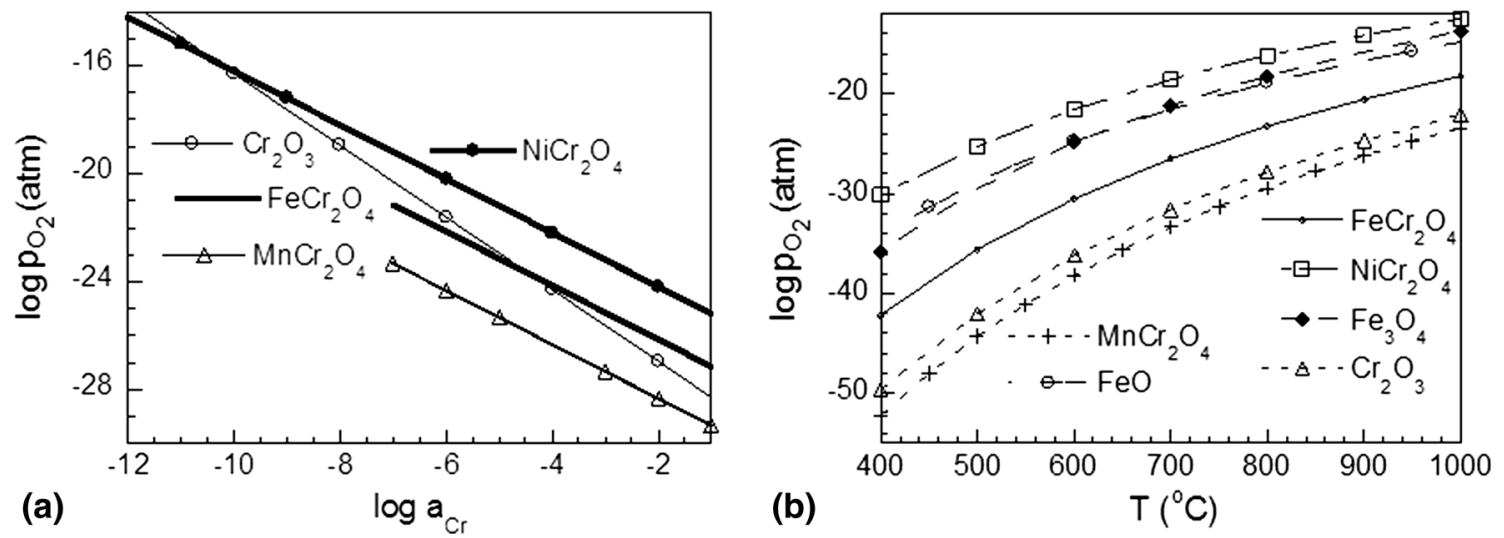

Fig. 9 (a) Thermochemical stability of oxides as a function of chromium activity at $750{ }^{\circ} \mathrm{C}$. $\Delta G$ for Reactions $1-3$ are $-870.018,-1104.3$, and $-1039.622 \mathrm{~kJ} / \mathrm{mol}$, respectively, at $750{ }^{\circ} \mathrm{C}$. The activities of $\mathrm{Fe}, \mathrm{Ni}$, and $\mathrm{Mn}$ in metallic nanonetworks are assumed to be $0.72,0.25$, and 0.01 respectively. (b) Thermochemical stability of oxides as a function of temperature

and its concentration at the end of the metallic networks can be much lower than that in the alloy. As the Cr concentration drops $\mathrm{t}$ less than $3.4 \times 10^{-3}$ at. $\%$ in metal, $\mathrm{FeCr}_{2} \mathrm{O}_{4}$ can become more stable, which can prevent protective $\mathrm{Cr}_{2} \mathrm{O}_{3}$ from forming.

The metallic nanonetworks or nanoparticles can be formed in the thermal growth process of the oxide scales (Ref 6), or may remain in the scale during continued oxidation. However, the critical issue is that the presence of metallic phase can, in turn, affect the diffusion process and the distribution of $\mathrm{Cr}$ in the oxide scales. If the oxidation process does not form such metallic nanonetworks, then $\mathrm{Cr}$ accumulates at the flat alloyoxide boundary, and a protective $\mathrm{Cr}_{2} \mathrm{O}_{3}$ layer will form by regular diffusion process. If oxidation process results in the formation of metallic nanonetworks, then $\mathrm{Cr}$ will be diffused out and diluted into the oxide layer, and may not accumulate at the alloy-oxide boundary to form a dense $\mathrm{Cr}_{2} \mathrm{O}_{3}$ layer. This process can lead to accelerated oxidation and can subsequently lead to breakaway oxidation.

The order of decreasing chemical stability of spinel phases is $\mathrm{MnCr}_{2} \mathrm{O}_{4}>\mathrm{FeCr}_{2} \mathrm{O}_{4}>\mathrm{NiCr}_{2} \mathrm{O}_{4}$ (Fig. 9b). $\mathrm{MnCr}_{2} \mathrm{O}_{4}$ is more stable than $\mathrm{Cr}_{2} \mathrm{O}_{3}$ even though the activity of $\mathrm{Cr}$ is 1 ( $\mathrm{Ref} 16$, 17). Since the increasing $\mathrm{Cr}$ concentration will enhance the formation of stable $\mathrm{Cr}_{2} \mathrm{O}_{3}$, the maximum chromium concentration $\left(M C_{C r}\right)$ in metals in which spinel can remain in a stable phase also increases in the same order. Our calculations show $M C_{\mathrm{Cr}}$ values of $3.4 \times 10^{-3}$ at. $\%$ for $\mathrm{FeCr}_{2} \mathrm{O}_{4}$ and $5.1 \times$ $10^{-11}$ at.\% for $\mathrm{NiCr}_{2} \mathrm{O}_{4}$ (Fig. 9a). The spinel in the oxide scales on 321 ss actually is the solid solution of $(\mathrm{Mn}, \mathrm{Fe}) \mathrm{Cr}_{2} \mathrm{O}_{4}$. The stability of solid solution of $(\mathrm{Mn}, \mathrm{Fe}) \mathrm{Cr}_{2} \mathrm{O}_{4}$ is between those of $\mathrm{FeCr}_{2} \mathrm{O}_{4}$ and $\mathrm{MnCr}_{2} \mathrm{O}_{4}$. Therefore, the critical concentration of $\mathrm{Cr}$ in the metal phase to make spinel stabler than $\mathrm{Cr}_{2} \mathrm{O}_{3}$ is between $3.4 \times 10^{-3}$ at. $\%$ and near 100 at. $\%$, which depends on the content of $\mathrm{Mn}$ in spinel. An increase in the Mn content would increase the stability of the solid solution. It is possible that when $\mathrm{Mn}$ is concentrated enough, the alloy would develop a spinel phase in the scales without a protective $\mathrm{Cr}_{2} \mathrm{O}_{3}$ layer. TEM-EDX analysis indicates that the ratio of $\mathrm{Fe} / \mathrm{Mn}$ is $13.1 / 1.8$ in the oxide phase (see Table 1 ). The value for $x$ in the spinel of $\mathrm{Fe}_{1-x} \mathrm{Mn}_{x} \mathrm{Cr}_{2} \mathrm{O}_{4}$ is $\approx 0.12$, whereas the content of $\mathrm{Cr}$ in metallic nanonetwork is 1.6 at.\%. The $\mathrm{Mn}$ concentration in oxide and $\mathrm{Cr}$ concentration in metal may not be accurately determined because of the overlaps of $\mathrm{Mn}-\mathrm{K}_{\alpha}$ and $\mathrm{Cr}-\mathrm{K}_{\beta}$ and their low concentrations. However, the results indicate that the critical $\mathrm{C}_{\mathrm{Cr}}$ in metallic nanonetwork can be
$>1$ at. $\%$, if there is enough $\mathrm{Mn}$ in the oxide layer. Type $321 \mathrm{ss}$ contains manganese, and the formation of an oxide scale without $\mathrm{Cr}_{2} \mathrm{O}_{3}$ layer is observed in the breakaway region. This result confirms that the manganese in alloy can diffuse to oxide layer and increase the stability of the spinel phase, which leads to the formation of a nonprotective oxide layer without $\mathrm{Cr}_{2} \mathrm{O}_{3}$ when the $\mathrm{Cr}$ concentration in metallic nanonetworks decreases.

Since oxygen diffusion in spinel is much faster than in $\mathrm{Cr}_{2} \mathrm{O}_{3}$ (see Table 2), the oxidation rate in this region is also greater than that in the region with a protective $\mathrm{Cr}_{2} \mathrm{O}_{3}$ layer. Our analysis suggests that breakaway oxidation is initiated upon the formation of a continuous metallic network within the scales.

Carburization of alloys was often observed at high temperature in a gas environment with $\mathrm{CO}_{2}(\operatorname{Ref} 1,20)$. The diffusion rate of carbon in the oxide scales is negligible (Ref 21). Diffusion of carbon through oxide is very difficult. However, carbon can dissolve and diffuse through metals (Ref 6). If there is a metallic nanonetwork through the oxide layer, then carbon can rapidly diffuse through these nanonetworks in the oxide layer. Figure 10(a) shows that carbides were observed at the grain boundary. Small crystals are also evident in grains under the nonprotective region (Fig. 10b). In contrast, no such small crystals are observed in grains under the protective region (Fig. 10c). EDX analysis indicated that the concentrations of carbon and chromium are high in these small crystals. Weak diffraction peaks from $\mathrm{Cr}_{23} \mathrm{C}_{6}$ are observed in the nonprotective region by synchrotron nanobeam XRD analysis. Although the thickness of the oxide scale at the protective region is much smaller than that at the nonprotective region, these carbide crystals could not be observed either by the SEM or the nanobeam XRD analysis. Therefore, it can be concluded that metallic nanonetwork provides a path for fast transport of carbon through oxide layer. The diffused carbon reacts with chromium in $321 \mathrm{ss}$ and affects the mobility of chromium, which can further increase the corrosion rate.

\subsection{Effect of Metallic Nanonetworks on the Diffusion Mechanism}

High-temperature oxidation can be affected by many factors, such as grain boundary diffusion and chromia evaporation. Several mechanisms were proposed to explain the breakaway 
Table 2 Diffusion data for metallic elements and oxygen in oxides and in metals

\begin{tabular}{|c|c|c|c|c|c|c|}
\hline Solvents & Diffusing element & $Q(\mathrm{~kJ} / \mathrm{mol})$ & $D_{\mathrm{O}}\left(\mathrm{cm}^{2} / \mathrm{s}\right)$ & $T\left({ }^{\circ} \mathrm{C}\right)$ & $D\left(\mathrm{~cm}^{2} / \mathrm{s}\right)$ & Ref. \\
\hline$\alpha-\mathrm{Fe}-\mathrm{Cr}$ & $\mathrm{Cr}$ & 230.48 & 1.29 & 750 & $5.6 \times 10^{-12}$ & 44 \\
\hline$\alpha-\mathrm{Fe}$ & $\mathrm{Fe}$ & 238.61 & 1.9390 & 750 & $1.3 \times 10^{-12}$ & 45 \\
\hline$\alpha-\mathrm{Fe}$ & $\mathrm{O}$ & 92.1 & 0.00378 & 750 & $7.5 \times 10^{-8}$ & 46 \\
\hline$\gamma$-Fe-Cr & $\mathrm{Cr}$ & 180.00 & 0.0005 & 750 & $3.2 \times 10^{-13}$ & 45 \\
\hline$\gamma$-Fe-Cr-Ni & $\mathrm{Fe}$ & 209.30 & 0.003 & 750 & $6.2 \times 10^{-14}$ & 45 \\
\hline$\gamma-\mathrm{Fe}$ & $\mathrm{O}$ & 166 & 1.3 & 750 & $4.34 \times 10^{-9}$ & 48 \\
\hline Ni metal & $\mathrm{Cr}$ & 171 & 0.03 & 750 & $5.7 \times 10^{-11}$ & 50 \\
\hline Ni metal & $\mathrm{Fe}$ & 133 & $7.3 \times 10^{-4}$ & 750 & $1.2 \times 10^{-10}$ & 44 \\
\hline Ni metal & $\mathrm{O}$ & 164 & 0.049 & 750 & $2.07 \times 10^{-10}$ & 49 \\
\hline Ni Metal & $\mathrm{C}$ & 138 & 0.08 & 750 & $7.19 \times 10^{-9}$ & 19 \\
\hline $\mathrm{Cr}_{2} \mathrm{O}_{3}$ & $\mathrm{Cr}$ & 280 & $5.84 \times 10^{-9}$ & 1300 & $3.1 \times 10^{-18}$ & 51 \\
\hline $\mathrm{Cr}_{2} \mathrm{O}_{3}$ & $\mathrm{Fe}$ & 237 & $4.4 \times 10^{-7}$ & 720 & $1.2 \times 10^{-19}$ & 52 \\
\hline $\mathrm{Cr}_{2} \mathrm{O}_{3}$ & $\mathrm{O}$ & 422 & 15.9 & 750 & $4.4 \times 10^{-21}$ & 53 \\
\hline $\mathrm{Cr}_{2} \mathrm{O}_{3}$ & $\mathrm{H}$ & 70.3 & $1.78 \times 10^{-5}$ & 750 & $4.57 \times 10^{-9}$ & 54 \\
\hline Spinel oxide scale & $\mathrm{O}$ & & & 800 & $3.1 \times 10^{-12}$ & 55 \\
\hline $\mathrm{CoCr}_{2} \mathrm{O}_{4}$ & $\mathrm{Cr}$ & 292 & 2 & 750 & $2.5 \times 10^{-15}$ & 56 \\
\hline $\mathrm{NiCr}_{2} \mathrm{O}_{4}$ & $\mathrm{Cr}$ & 303 & 0.74 & 750 & $2.6 \times 10^{-16}$ & 57 \\
\hline Spinel oxide scale & $\mathrm{Cr}$ & & & 750 & $1 \times 10^{-19}$ & 58 \\
\hline $\mathrm{MnCr}_{2} \mathrm{O}_{4}$ & $\mathrm{Cr}$ & & & 800 & $9.7 \times 10^{-13}$ & 18 \\
\hline $\mathrm{MnCr}_{2} \mathrm{O}_{4}$ & $\mathrm{Mn}$ & & & 800 & $1.7 \times 10^{-12}$ & 18 \\
\hline $\mathrm{MnCr}_{2} \mathrm{O}_{4}$ & $\mathrm{Fe}$ & & & 800 & $1.2 \times 10^{-12}$ & 18 \\
\hline
\end{tabular}
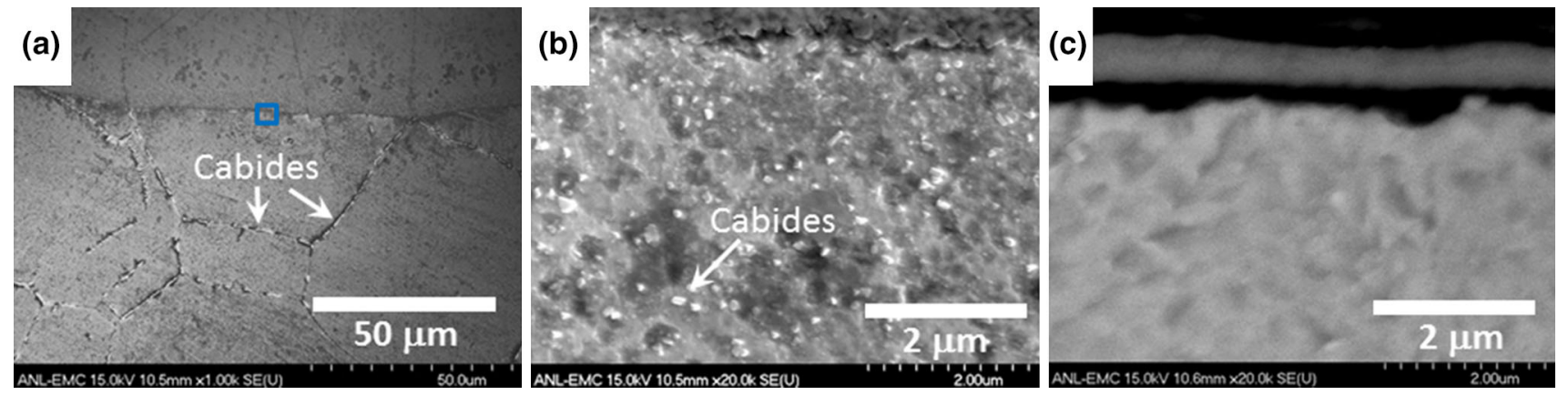

Fig. 10 SEM images of cross section of 321ss after 24-h exposure to pure $\mathrm{CO}_{2}$ at $750{ }^{\circ} \mathrm{C}$ : (a) At breakaway region (b) High-magnification images from the blue square region of a, EDX analysis indicating that there is more $\mathrm{Cr}$ and $\mathrm{C}$ at the bright particles than in the dark region; (c) At protective region, a nice oxide scale was observed. The bright particles (chromium carbides) are not observed here (Color figure online)

oxidation (Ref 22-25). However, these mechanisms may not explain all the observations from this experiment. The aforementioned phase-stability analysis indicates that the primary phase at the nonprotective region is spinel. Thick spinel layer of over hundred micrometers obviously cannot protect the alloy from continued oxidation at the nonprotected region, since oxygen can rapidly diffuse through spinel. In contrast, the alloys can be protected by a $\mathrm{Cr}_{2} \mathrm{O}_{3}$ layer with a thickness of only $\sim 1 \mu \mathrm{m}$ when $321 \mathrm{ss}$ is oxidized in $21 \% \mathrm{O}_{2}-79 \% \mathrm{CO}_{2}$. Therefore, the key issue to understand the breakaway oxidation is what happens at the reaction front of the alloy-oxide boundary to suppress the formation of a protective $\mathrm{Cr}_{2} \mathrm{O}_{3}$. Figure 2(c) shows the reaction front processes in a grain. Regular grain boundary diffusion obviously does not play a significant role in the front reaction in these grains. Typically, grain boundary diffusion increases alloy oxidation. However, Figure 2(c) indicates that fast oxidation is terminated at grain boundary and that such a fast oxidation phenomenon cannot be explained by classic grain boundary diffusion. $\mathrm{Cr}_{2} \mathrm{O}_{3}$ evaporation typically occurs in an environment with steam. However, when an experiment is conducted in pure $\mathrm{CO}_{2}$ without steam, the effect of $\mathrm{Cr}_{2} \mathrm{O}_{3}$ evaporation can also be ignored. These factors that affect the oxidation process cannot be used to explain the observations in our experiments. We will focus our discussion on whether the breakaway oxidation is led by internal oxidation or a new mechanism of metallic nanonetwork-assisted oxidation.

Since diffusion plays an important role in alloy oxidation, it is important to understand the diffusion mechanism involved in high-temperature oxidation. Figure 11 shows three types of diffusion mechanisms that we plan to discuss in this paper. In general, it is considered that cations such as $\mathrm{Fe}^{2+}, \mathrm{Mn}^{2+}$, and $\mathrm{Cr}^{3+}$ diffuse outward to form the oxide scales. Figure 5(e) shows that there are two layers in the oxide scales in the protective region. The outer scale consists primarily of spinel (Fe, $\mathrm{Mn}) \mathrm{Cr}_{2} \mathrm{O}_{4}$, and the primary phase of the inner layer is $\mathrm{Cr}_{2} \mathrm{O}_{3}$. The $\mathrm{Cr}$ concentration near the alloy-oxide boundary is close to the $\mathrm{Cr}$ concentration at the center of the alloy 

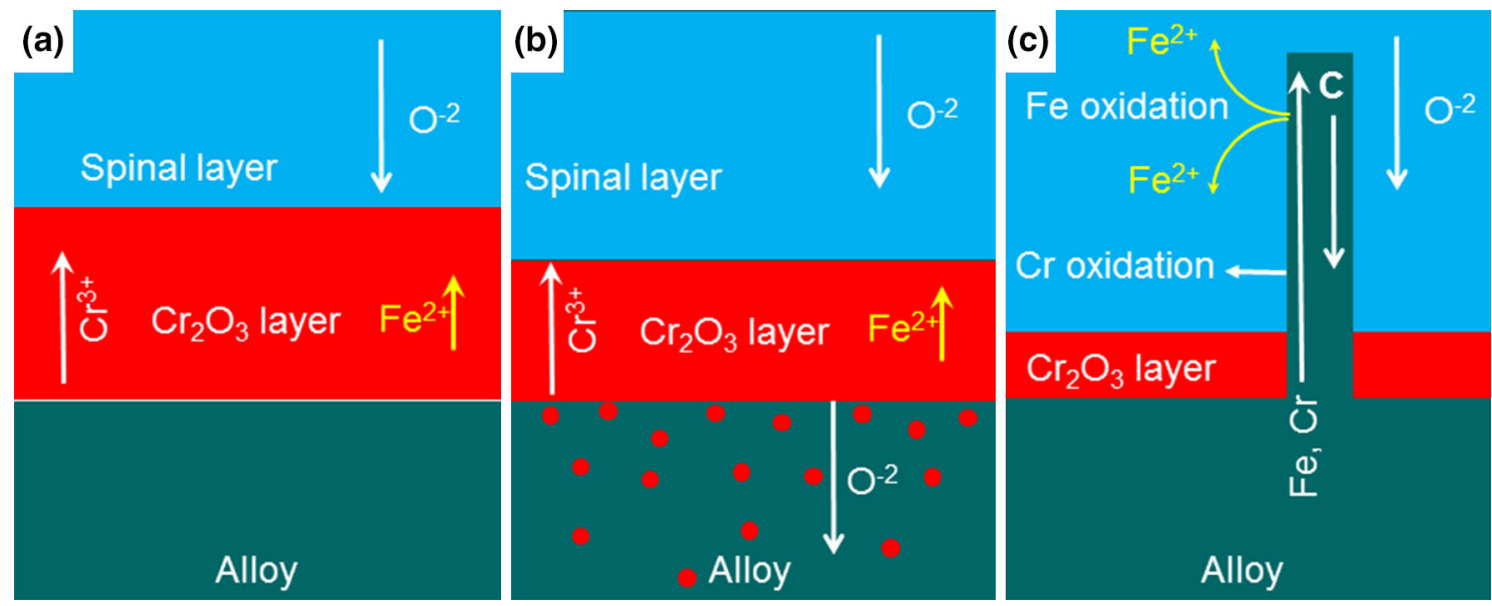

Fig. 11 Diffusion models. Type A: protective model, $\mathrm{Fe}^{2+}$ and $\mathrm{Cr}^{3+}$ cations diffuse out, and $\mathrm{O}^{2-}$ inward diffuses through oxide scales. Type $\mathrm{B}$ : internal oxidation model, $\mathrm{O}^{2-}$ inward diffuses through oxide scales and enter alloys. Type $\mathrm{C}$ : metallic nanonetwork-assisted oxidation, neutral $\mathrm{Fe}$, and $\mathrm{Cr}$ outward diffuse and carbon diffuse inward through metallic nanonetworks. $\mathrm{O}^{2-}$ inward diffuses through oxide networks

(18.3 at.\%), which indicates that the $\mathrm{Cr}$ depletion near the boundary is limited. Since the $p_{\mathrm{O}_{2}}$ in the inner layer near the alloy-oxide boundary is much lower, the $\mathrm{FeCr}_{2} \mathrm{O}_{4}$ spinel does not form. Although $\mathrm{MnCr}_{2} \mathrm{O}_{4}$ spinel can form in the inner layer, the low concentration of $\mathrm{Mn}$ in alloy indicates that the concentration of $\mathrm{MnCr}_{2} \mathrm{O}_{4}$ spinel is not high enough to form a continuous tunnel for the outward diffusion of $\mathrm{Fe}^{2+} . \mathrm{Fe}^{2+}$ has to diffuse through the $\mathrm{Cr}_{2} \mathrm{O}_{3}$ to the outer layer where the $p_{\mathrm{O}_{2}}$ is high enough to form stable $\mathrm{FeCr}_{2} \mathrm{O}_{4}$. Since the $\mathrm{Fe}^{2+}$ diffusion rate through $\mathrm{Cr}_{2} \mathrm{O}_{3}$ is very low (see Table 2), the growth rate of the scale is also low, and the scale is protective. The diffusion mechanism for the protective region corresponds to Type A, as shown in Fig. 11(a).

Internal oxidation has been studied for several decades (Ref 8, 26-40). The mechanism is extensively discussed in the literature. The inward diffusion and precipitation of oxygen in metal were considered to have caused the alloy oxidation (shown in Fig. 11b). When the concentration of an active alloying component is increased above a critical concentration, the oxidation process results in the formation of a protective oxide scale, and the alloy is minimally oxidized internally.

Originally, the application of the concept of internal oxidation was limited to low concentration of an active element in a relatively inert substrate (Ref 26-36). However, the concept has been widely used for analyzing oxidation in concentrated alloys in many Fe- and Ni-based alloy systems with high concentrations of active elements (Ref 7, 39, 41-45). Although internal oxidation is always possible during high-temperature oxidation, the question is whether internal oxidation is the primary cause for breakaway oxidation. In general, if the oxygen inward diffusion flux is larger than the chromium outward diffusion flux, internal oxidation plays a major role in oxidation. Therefore, the required condition for the internal oxidation mechanism in $\mathrm{Cr}$ containing alloy is as follows (Ref 40):

$N_{\mathrm{o}} D_{\mathrm{o}}>N_{\mathrm{cr}} D_{\mathrm{cr}}$

where $N_{\mathrm{O}}$ is the concentration of oxygen in metal (in mole fraction), $D_{\mathrm{O}}$ is the diffusion coefficient of oxygen in the metal, $N_{\mathrm{Cr}}$ is the concentration of $\mathrm{Cr}$ in metal (in mole fraction), and $D_{\mathrm{Cr}}$ is the diffusion coefficient of $\mathrm{Cr}$ in the metal.
If there is no $\mathrm{Mn}, N_{\mathrm{Cr}}<3.4 \times 10^{-5}$ to stabilize $\mathrm{FeCr}_{2} \mathrm{O}_{4}$. However, the above TEM-EDX analysis indicates that $N_{\mathrm{Cr}}$ can be 0.016 , if the spinel phase of the oxide layer contains $\mathrm{Mn}$ with $x \approx 0.12$ in $\mathrm{Fe}_{1-x} \mathrm{Mn}_{x} \mathrm{Cr}_{2} \mathrm{O}_{4}$. At the inner oxide layer, the inward diffusion of oxygen is retarded by the external oxide layer. The partial pressure of the oxygen is very low, and so the iron content in the metallic nanonetwork can be as high as 72 at.\%. Synchrotron nanobeam XRD result indicates the presence of both ferritic and austenitic iron in the metallic phase. Table 2 shows the diffusion coefficients for various elements (Ref 46-60). The diffusion coefficients of $\mathrm{Cr}$ and $\mathrm{Fe}$ in $\alpha$-Fe are $5.6 \times 10^{-12} \mathrm{~cm}^{2} / \mathrm{s}$ (Ref 46) and $1.3 \times 10^{-12} \mathrm{~cm}^{2} / \mathrm{s}$ (Ref 47), respectively, at $750{ }^{\circ} \mathrm{C}$. Therefore, the $N_{\mathrm{Cr}} D_{\mathrm{Cr}}$ is $\approx 1 \times 10^{-13} \mathrm{~mol} \mathrm{~cm} / \mathrm{s}$, and the $N_{\mathrm{Fe}} D_{\mathrm{Fe}}$ is $\approx 9.4 \times 10^{-13} \mathrm{~mol}$ $\mathrm{cm}^{2} / \mathrm{s}$ at $750{ }^{\circ} \mathrm{C}$. The recent experiment indicated that the diffusion coefficient of oxygen in $\alpha$-iron is $7.5 \times 10^{-8} \mathrm{~cm}^{2} / \mathrm{s}$ (Ref 48), and the solubility of oxygen in $\alpha-F e$ under the equilibrium of $\mathrm{Fe}-\mathrm{FeO}$ is $3.8 \times 10^{-7}$ ( $\mathrm{Ref} 49$ ). Therefore, the value for $N_{\mathrm{O}} D_{\mathrm{O}}$ in $\alpha-\mathrm{Fe}$ is $\approx 2.8 \times 10^{-14} \mathrm{~mol} \mathrm{~cm} / \mathrm{s}$ at $750{ }^{\circ} \mathrm{C}$.

The diffusion rates of both metallic elements iron and chromium and oxygen in $\gamma$-iron are smaller than those in $\alpha$-Fe. The diffusion coefficient of $\mathrm{Cr}$ and $\mathrm{Fe}$ in $\gamma$-iron is $3.2 \times 10^{-13}$ $\mathrm{cm}^{2} / \mathrm{s}$ (Ref 47) and $6.2 \times 10^{-14} \mathrm{~cm}^{2} / \mathrm{s}$ (Ref 47), respectively, at $750{ }^{\circ} \mathrm{C}$. Therefore, the $N_{\mathrm{Cr}} D_{\mathrm{Cr}}$ is $\approx 5.8 \times 10^{-15} \mathrm{~mol} \mathrm{~cm} / \mathrm{s}$, and the $N_{\mathrm{Fe}} D_{\mathrm{Fe}}$ is $\approx 4.6 \times 10^{-14} \mathrm{~mol} \mathrm{~cm} / \mathrm{s}$ at $750{ }^{\circ} \mathrm{C}$. The recent experiment indicated that the diffusion coefficient of oxygen in $\gamma$-iron is $4.3 \times 10^{-9} \mathrm{~cm}^{2} / \mathrm{s}$ (Ref 50$)$. The solubility of oxygen in $\gamma$-iron under the Fe-FeO equilibrium is $4.6 \times 10^{-7} \mathrm{~cm}^{2} / \mathrm{s}$ (Ref 49). Therefore, the $N_{\mathrm{O}} D_{\mathrm{O}}$ in $\gamma$-iron is $\approx 2 \times$ $10^{-16} \mathrm{~mol} \mathrm{~cm} / \mathrm{s}$ at $750{ }^{\circ} \mathrm{C}$.

It seems that the oxygen inward diffusion flux rate is comparable to the chromium outward diffusion flux under the equilibrium of $\mathrm{Fe}-\mathrm{FeO}$. However, the nanobeam XRD analysis indicates that $\mathrm{FeO}$ does not form in the oxide layer on the surface of $321 \mathrm{ss}$. $\mathrm{FeO}$ reacts with $\mathrm{Cr}_{2} \mathrm{O}_{3}$ and forms stable $\mathrm{FeCr}_{2} \mathrm{O}_{4}$. The $p_{\mathrm{O}_{2}}$ of the $\mathrm{FeCr}_{2} \mathrm{O}_{4}$ is approximately five orders of magnitude lower than $\mathrm{FeO}$ at $750{ }^{\circ} \mathrm{C}$ (Fig. 9). The solubility of oxygen in $\alpha$-Fe under the equilibrium of $\mathrm{Fe}-\mathrm{FeCr}_{2} \mathrm{O}_{4}$ should be much lower than the solubility of oxygen in $\alpha$-Fe under the $\mathrm{Fe}-\mathrm{FeO}$ equilibrium, since oxygen can react with chromium in metallic nanonetwork to form $\mathrm{FeCr}_{2} \mathrm{O}_{4}$. Therefore, the $N_{\mathrm{O}} D_{\mathrm{O}}$ 
$<N_{\mathrm{Cr}} D_{\mathrm{Cr}}<N_{\mathrm{Fe}} D_{\mathrm{Fe}}$ in the metallic nanonetwork in the oxide layer of the nonprotective region on the surface of $321 \mathrm{ss}$. The actual oxygen inward diffusion flux should be much lower than $N_{\mathrm{Cr}} D_{\mathrm{Cr}}$ after oxygen diffusion is further retarded by the outer layer of the oxide scales. The oxygen concentration in the metallic nanonetwork may not reach the saturated concentration. In contrast, the concentration of $\mathrm{Cr}$ and $\mathrm{Fe}$ can be much higher than that of oxygen, when the metallic networks connect to the alloy substrate. This leads to a faster outward diffusion of $\mathrm{Cr}$ and $\mathrm{Fe}$ than the inward diffusion of oxygen through metallic nanonetworks. If $N_{\mathrm{O}} D_{\mathrm{O}}<N_{\mathrm{Cr}} D_{\mathrm{Cr}}$, internal oxidation may not play a major role for alloy oxidation, although internal oxidation can still occur.

Internal oxidation mechanism cannot fully explain our experimental observations either. In general, there are three types of oxidation: (i) exclusive internal oxidation without external scales; (ii) both internal oxidation and scale formation; and (iii) exclusive external scales. Type (i) obviously is not applicable to 321 ss because external scales have been observed after exposure to $\mathrm{CO}_{2}$ at $750{ }^{\circ} \mathrm{C}$. According to the theory of internal oxidation, the required chromium concentration to form an exclusive external scale is calculated by the following equation:

$N_{\mathrm{Cr}}^{\mathrm{O}}=\left(\frac{\pi g *}{3} \frac{V_{\mathrm{m}}}{V_{\mathrm{CrO}_{1.5}}} \frac{N_{\mathrm{O}}^{(\mathrm{s})} D_{\mathrm{O}}}{D_{\mathrm{Cr}}}\right)^{1 / 2}$,

where the factor $g^{*}$ is generally approximated as 0.3 (Ref 36). $V_{\mathrm{m}}$ and $V_{\mathrm{CrO} 1.5}$ are the molar volumes of alloy and oxide, respectively, which were assumed as 7 and $14.6 \mathrm{~cm}^{3} /$ mole, respectively. $N$ is oxygen solubility in the metal, $D_{\mathrm{O}}$ is diffusivity of oxygen in the metal, and $D_{\mathrm{Cr}}$ is the diffusion coefficient of $\mathrm{Cr}$ in the metal.

For an austenitic alloy, the diffusivity of oxygen and chromium are available in the literature. $D_{\mathrm{Cr}}$ is $3.2 \times 10^{-13}$ $\mathrm{cm}^{2} / \mathrm{s}$, and $D_{\mathrm{O}}$ is $4.3 \times 10^{-9} \mathrm{~cm}^{2} / \mathrm{s}$ at $750{ }^{\circ} \mathrm{C}$. The oxygen solubility is $4.6 \times 10^{-7}$ at $750^{\circ} \mathrm{C}$ in $\gamma$-Fe under the equilibrium of $\mathrm{Fe}-\mathrm{FeO}$. The critical concentration $N$ should be $\approx 3$ at.\% at $750{ }^{\circ} \mathrm{C}$, based on the oxygen solubility in $\gamma$-Fe under the equilibrium of $\mathrm{Fe}-\mathrm{FeO}$. However, it should be noted that application of Eq 12 is limited to diluted alloys with concentration of active element $(B)<1$ at.\%. Equation 12 was also derived from a simple assumption that only simple oxides of $\mathrm{AO}_{x}$ and $\mathrm{BO}_{y}$ form in the oxidation process. For the $\mathrm{Fe}-\mathrm{Cr}$ alloys, the nanobeam XRD results indicate an absence of simple oxides such as $\mathrm{FeO}$ and $\mathrm{Cr}_{2} \mathrm{O}_{3}$ in the inner layer of the nonprotective region. The only oxide in the nonprotective layer on 321 ss is $\mathrm{AB}_{2} \mathrm{O}_{4}\left((\mathrm{Fe}, \mathrm{Mn}) \mathrm{Cr}_{2} \mathrm{O}_{4}\right)$. $\mathrm{FeO}$ was also not observed in the oxide scales of the protective region. The oxygen solubility in either $\gamma$-Fe and $\alpha$-Fe under the equilibrium of $\mathrm{Fe}$ $\mathrm{FeCr}_{2} \mathrm{O}_{4}$ is currently not available, and its value will be much lower than that under the equilibrium of $\mathrm{Fe}-\mathrm{FeO}$. Therefore, the critical concentration of $\mathrm{Cr}$ in steel for the formation of an exclusive external scale should be less than 3 at.\%. The concentration of $\mathrm{Cr}$ in $321 \mathrm{ss}$ is 18.3 at.\%. An exclusive external scale should form on $321 \mathrm{ss}$, theoretically. SEM cross-sectional images also indicate that an external scale was observed initially when $321 \mathrm{ss}$ was exposed to pure $\mathrm{CO}_{2}$ at $750{ }^{\circ} \mathrm{C}$, and the surface of $321 \mathrm{ss}$ was still protected by the external scales after exposure to $21 \% \mathrm{O}_{2}-79 \% \mathrm{CO}_{2}$ at $750{ }^{\circ} \mathrm{C}$ for $320 \mathrm{~h}$. Therefore, both theoretical and experimental results have proven that an exclusive external scale can form on $321 \mathrm{ss}$ with $\mathrm{Cr}$ content of 17.3 wt.\% initially. If an exclusive external scale can form, the Type (ii) internal oxidation with external scale should not occur. Although the scale broke away late, internal oxidation mechanism cannot really explain why the external scale broke away after it was initially formed.

Results from Rapp's experiment indicates that less-active alloying element is needed for the transition of internal oxidation to external oxidation at low $p_{\mathrm{O}_{2}}$ than that at high $p_{\mathrm{O}_{2}}$ (Ref 35, 36). In the breakaway region of $321 \mathrm{ss}$, the $p_{\mathrm{O}_{2}}$ in the inner oxide layer is low since the oxygen inward diffusion is retarded by the relatively thick oxide layer. According to Rapp's results, less $\mathrm{Cr}$ content would be required to prevent internal oxidation. When an alloy can form a protective external oxide scale at the gas-oxide surface, it is not reasonable to consider the observation in Fig. 4(a) to be "internal oxidation zone" where $p_{\mathrm{O}_{2}}$ at the inner-layer is lower than that at the outer layer at the gas-oxide surface.

The theoretical density of $\mathrm{FeCr}_{2} \mathrm{O}_{4}$ spinel is $4.7 \mathrm{~g} / \mathrm{cm}^{3}$. The density of $321 \mathrm{ss}$ is $7.92 \mathrm{~g} / \mathrm{cm}^{3}$. If oxygen inward diffusion is the dominant mechanism, then the mass increase and the density decrease during the oxidation of $321 \mathrm{ss}$ to $\mathrm{FeCr}_{2} \mathrm{O}_{4}$ should lead to a large volume expansion and deformation of the alloy grains. However, the straight grain boundary at the interface of oxide-metal in Fig. 2(c) (indicated by the green arrow) shows that the former grains do not deform after oxidation, which also indicates that the oxygen inward diffusion through metallic networks is not the predominant mechanism. The iron content in the metallic nanonetwork in the oxide layer is 72 at.\%. However, the $\mathrm{Cr}$ content in the metallic nanonetwork near the alloy substrate has dropped to 1.5 at.\%, which is too low to form a $\mathrm{Cr}_{2} \mathrm{O}_{3}$ protective layer. Therefore, the oxidation of the major component of the alloy, Fe, occurs in the metallic nanonetwork region, instead of the interior of the alloy.

Therefore, the classical internal oxidation mechanism (developed for dilute alloys) may not be the best mechanism to explain the breakaway oxidation of $321 \mathrm{ss}$. We believe that the rapid oxidation phenomenon can be better explained if we carefully consider the other possible diffusion mechanism shown in Fig. 10(c). For internal oxidation mechanism, the volume of oxide is less than the volume of metal. In the case of Ag-In alloys, Rapp found that the volume fraction was less than 0.3 for internal oxidation. For the opposite case, in which the volume of oxide is more than the volume of metal, the effect of the metal in the oxide layer on the oxidation has not been studied yet. If these metallic particles in the oxide layer are isolated, diffusion mechanism may not been affected. However, if these metallic particles connect together to form a nanowire in the oxide layer, as shown in Fig. 11(c), the diffusion mechanism at the reaction front will be dramatically changed.

The difference in the distributions of $\mathrm{Fe}$ between breakaway and protective regions indicates that the metallic networks play an important role in the transport of Fe. Rapid transport of $\mathrm{Fe}$ outward through the $\mathrm{Ni}$-enriched metallic networks in the breakaway region results in high $\mathrm{Fe}$ content in the outer layer. Such a process does not occur in the protective region. Typically, $\mathrm{Cr}, \mathrm{Fe}$, and $\mathrm{Mn}$ diffuse outward through the oxide scales as cations. If there are no metallic nanonetworks, then their outward diffusion rates will be slow because the cation diffusion rates through $\mathrm{Cr}_{2} \mathrm{O}_{3}$ are very low (see Table 2). However, the diffusion rates of these neutral metal atoms through metallic nanonetworks are much higher than in the $\mathrm{Cr}_{2} \mathrm{O}_{3}$ layers. For example, $D_{\mathrm{Fe}}$ in Ni metal is $1 \times 10^{9}$ larger than in $\mathrm{Cr}_{2} \mathrm{O}_{3}$. The diffusions of $\mathrm{Cr}, \mathrm{Fe}$, and $\mathrm{Mn}$ in Ni metal are 
also faster than those in spinel. The metallic nanonetworks act as rapid diffusion tunnels to break through the diffusion barrier of the $\mathrm{Cr}_{2} \mathrm{O}_{3}$ layers that can protect the alloy from continued high-temperature oxidation. Thus, the transportation mechanism is fundamentally changed.

The diffusion data for oxygen in the oxide scales are not available at $750{ }^{\circ} \mathrm{C}$. It was reported that $D_{\mathrm{O}}$ in the oxide scales is $3.1 \times 10^{-12} \mathrm{~cm}^{2} / \mathrm{s}$ at $800^{\circ} \mathrm{C}$ (Ref 57). Nanobeam XRD analysis indicated that spinel is the only oxide phase in the scale layer at the nonprotective region. Oxygen concentration in spinel $\left(\mathrm{FeCr}_{2} \mathrm{O}_{4}\right)$ is 0.57 , which is much higher than that in both $\alpha-\mathrm{Fe}$ and $\gamma-\mathrm{Fe} . N_{\mathrm{O}} D_{\mathrm{O}}$ in the oxide layer is $1.8 \times 10^{-12}$ mole $\mathrm{cm}^{2} / \mathrm{s}$ at $800{ }^{\circ} \mathrm{C}$. $D_{\mathrm{O}}$ in $\alpha$-Fe and $\gamma$-Fe are $1.2 \times 10^{-7}$ and $1.1 \times 10^{-8} \mathrm{~cm}^{2} / \mathrm{s}$, respectively, at $800{ }^{\circ} \mathrm{C} . N_{\mathrm{O}}$ in $\alpha-\mathrm{Fe}$ and $\gamma-\mathrm{Fe}$ are $7.2 \times 10^{-7}$ and $7.8 \times 10^{-7}$, respectively, under the equilibrium of $\mathrm{Fe}-\mathrm{FeO}$ at $800{ }^{\circ} \mathrm{C} . N_{\mathrm{O}} D_{\mathrm{O}}$ in $\alpha-\mathrm{Fe}$ and $\gamma$-Fe are

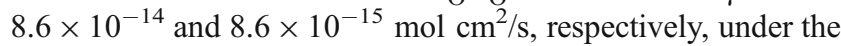
equilibrium of $\mathrm{Fe}-\mathrm{FeO}$ at $800{ }^{\circ} \mathrm{C}$. Therefore, the oxygen flux through spinel is one or two orders of magnitude higher than that in metallic nanonetwork, if the oxygen solubility can reach the saturated concentration under the equilibrium of $\mathrm{Fe}-\mathrm{FeO}$ at $800{ }^{\circ} \mathrm{C}$. However, since $\mathrm{FeO}$ has reacted with $\mathrm{Cr}_{2} \mathrm{O}_{3}$ to form $\mathrm{FeCr}_{2} \mathrm{O}_{4}$, the actual equilibrium should be with $\mathrm{FeCr}_{2} \mathrm{O}_{4}$. The solubility of oxygen under the equilibrium of $\mathrm{Fe}-\mathrm{FeCr}_{2} \mathrm{O}_{4}$ should be much smaller than that under the equilibrium of $\mathrm{Fe}$ $\mathrm{FeO}$ since the $p_{\mathrm{O}_{2}}$ under the equilibrium of $\mathrm{Fe}-\mathrm{FeCr}_{2} \mathrm{O}_{4}$ is five orders of magnitude smaller than that under the equilibrium of Fe-FeO. $N_{\mathrm{O}} D_{\mathrm{O}}$ in $\alpha$-Fe and $\gamma$-Fe under the equilibrium of $\mathrm{Fe}-$ $\mathrm{FeCr}_{2} \mathrm{O}_{4}$ should also be much smaller than that under the equilibrium of $\mathrm{Fe}-\mathrm{FeO}$ at $800{ }^{\circ} \mathrm{C} . N_{\mathrm{O}} D_{\mathrm{O}}$ in spinel will be much larger than that in metallic nanonetwork at $800{ }^{\circ} \mathrm{C}$. At $750{ }^{\circ} \mathrm{C}$, this order will not change. Therefore, the rapid oxygen inward diffusion at the nonprotective region on $321 \mathrm{ss}$ should be through spinel, instead of through metallic nanonetworks.

A transportation mechanism that leads to breakaway oxidation can be proposed as the following: $\mathrm{Cr}, \mathrm{Fe}$, and $\mathrm{Mn}$ transport outward, and carbon diffuses inward through the metallic networks, while oxygen diffuses inward through the spinel phase. Since both the metallic elements and oxygen transport through the fastest routes, the oxidation rate at the location adjacent to the metallic networks would be higher than that at the region without the metallic networks, leading to localized oxidation (see Fig. 1). Figure 4(b) shows that oxidation of $\alpha$ and $\varepsilon$ grains seem to initiate from the upper left corner of the grain. The oxide-alloy boundary forms an arc line with the center at the corner of the grain. The presence of the large dark region at the corner of the grain is due to the accumulation of oxides of $\mathrm{Cr}, \mathrm{Fe}$, and $\mathrm{Mn}$ transported via the metallic networks from the alloy. EDX analysis confirms high concentrations of $\mathrm{Cr}, \mathrm{Fe}, \mathrm{Mn}$, and $\mathrm{O}$ in the dark regions. The accumulation of the oxides, which forms the dark and thicker grain boundaries in the oxidized region, is evidence of outward diffusion of metallic elements. Meanwhile, the grain boundaries of the upper grains are not as straight as those near the oxidemetal boundary, most likely due to the insertion of $\mathrm{Cr}, \mathrm{Fe}$, and Mn oxides. For the grain $\beta$, the accumulation of the oxides of $\mathrm{Cr}, \mathrm{Fe}$, and $\mathrm{Mn}$ also leads to thicker upper boundaries. For the grain $\delta$, the oxidation initiates from two active sites, namely the upper corner and upper grain boundary. However, the thickness of the grain boundary with active sites is much greater than that without the active sites. These observations can be explained by the outward diffusion of metal atoms through the metallic network, but they cannot be explained by the inward diffusion of oxygen. $\mathrm{Cr}$ and $\mathrm{Fe}$ outward diffusions through metallic nanonetworks are explained as the mechanism responsible for the rapid oxidation when metallic networks connect to the alloy substrate. This metallic nanonetwork-assisted oxidation mechanism (MNAO) with different diffusion routes (see Fig. 11c) can clearly explain the experimental observation. Internal oxidation is due to the oxygen inward diffusion. In contrast, MNAO is due to the metallic elements' outward diffusion through metallic nanonetworks in a system with oxide multilayers. Since the proposal of the theory of oxidation by Wagner in 1933 (Ref 5), diffusions of charged species such as cations, anions, and electrons have been considered as the only avenue for transport in the oxide scales because the scales are usually considered to consist of only oxide phases. However, the formation of metallic nanonetworks in the oxide layers fundamentally changes the transport mechanism.

\subsection{Effect of Metallic Nanonetworks on the Phase Formation in Oxide Layers}

If there are no metallic nanonetworks, then the dual layer structure with $\mathrm{Cr}_{2} \mathrm{O}_{3}$ at the bottom is a stable structure because a thin layer of $\mathrm{Cr}_{2} \mathrm{O}_{3}$ of $1 \mu \mathrm{m}$ is good enough to protect the alloy from breakaway oxidation. $\mathrm{Fe}^{2+}$ has to diffuse through the dense $\mathrm{Cr}_{2} \mathrm{O}_{3}$ layer if there are no the metallic nanonetworks. However, the diffusion rate of $\mathrm{Fe}^{2+}$ in $\mathrm{Cr}_{2} \mathrm{O}_{3}$ is very low. $D_{\mathrm{Fe}}$ is only $1.2 \times 10^{-19} \mathrm{~cm}^{2} / \mathrm{s}$ at $750{ }^{\circ} \mathrm{C}$ (see Table 2) and is smaller than $D_{\mathrm{Cr}}\left(3.1 \times 10^{-18} \mathrm{~cm}^{2} / \mathrm{s}\right)$. Meanwhile, iron is difficult to be oxidized to $\mathrm{Fe}^{2+}$ in the inner oxide layer because oxygen is difficult to diffuse into $\mathrm{Cr}_{2} \mathrm{O}_{3}$ and $p_{\mathrm{O}_{2}}$ in a dense $\mathrm{Cr}_{2} \mathrm{O}_{3}$ layer is also very low. Therefore, the concentration of $\mathrm{Fe}^{2+}$ in $\mathrm{Cr}_{2} \mathrm{O}_{3}$ layer is low. The $\mathrm{Fe}^{2+}$ outward diffusion flux $\left(N_{\mathrm{Fe}} D_{\mathrm{Fe}}\right)$ is much smaller than the $\mathrm{Cr}^{3+}$ outward diffusion flux. A dense continuous $\mathrm{Cr}_{2} \mathrm{O}_{3}$ layer will form to protect the alloy from further oxidation.

However, if there are metallic nanonetworks, then metallic iron can be directly delivered to the spinel layer, where both $p_{\mathrm{O}_{2}}$ and the diffusion rate of $\mathrm{Fe}^{2+}$ are high. Iron is rapidly oxidized, and high concentration $\mathrm{Fe}^{2+}$ can diffuse back to react with $\mathrm{Cr}_{2} \mathrm{O}_{3}$ to form spinel:

$\mathrm{Fe}^{2+}+\mathrm{Cr}_{2} \mathrm{O}_{3}+\mathrm{O}^{2-}=\mathrm{FeCr}_{2} \mathrm{O}_{4}$

$\mathrm{Cr}_{2} \mathrm{O}_{3}$ was quickly consumed by reacting with a large amount of $\mathrm{Fe}^{2+}$. Finally, the amount of $\mathrm{Cr}_{2} \mathrm{O}_{3}$ remaining in the oxide layer is not enough to form a continuous layer. The protective layer and the phase structure with a dense $\mathrm{Cr}_{2} \mathrm{O}_{3}$ layer at the bottom are totally damaged because spinel is not as protective as $\mathrm{Cr}_{2} \mathrm{O}_{3}$. The formation of spinel provides a path for fast oxygen inward diffusion to increase $p_{\mathrm{O}_{2}}$ at the inner layer, thus, in turn, increasing the stability of $\mathrm{FeCr}_{2} \mathrm{O}_{4}$. This effect combined with the stabilizing effect of $\mathrm{Mn}^{2+}$ to form spinel. The protective $\mathrm{Cr}_{2} \mathrm{O}_{3}$ layer was almost totally removed in the nonprotective region of the $321 \mathrm{ss}$. The nanobeam XRD analysis on the inner layer of the nonprotective region confirmed the effect of metallic nanonetworks on the phase formation and the phase structure in the oxide layer after breakaway oxidation occurred (see Fig. 3a).

\subsection{Effect of Oxygen Partial Pressure on the Formation of Metallic Nanonetworks and Oxidation}

Breakaway oxidation was observed in 321 ss after exposure in pure $\mathrm{CO}_{2}$. Figure 1 shows that the development of local 


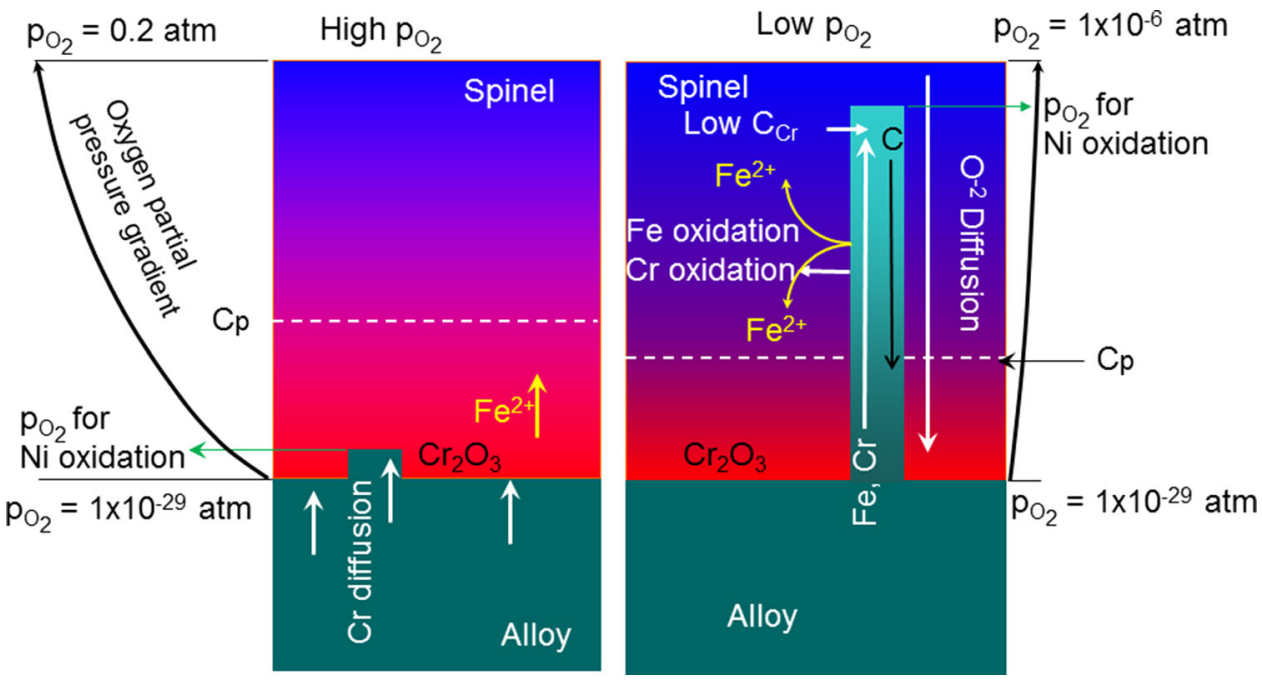

Fig. 12 Schematic of the effect of oxygen partial pressure on metallic nanonetwork-assisted oxidation. Oxygen diffuses fast in spinel, but slowly in $\mathrm{Cr}_{2} \mathrm{O}_{3}$. A metallic nanowire can directly deliver chromium metal to the nonprotective spinel layer when the low gradient of the oxygen partial pressure allows the metallic nanowire to grow sufficiently long
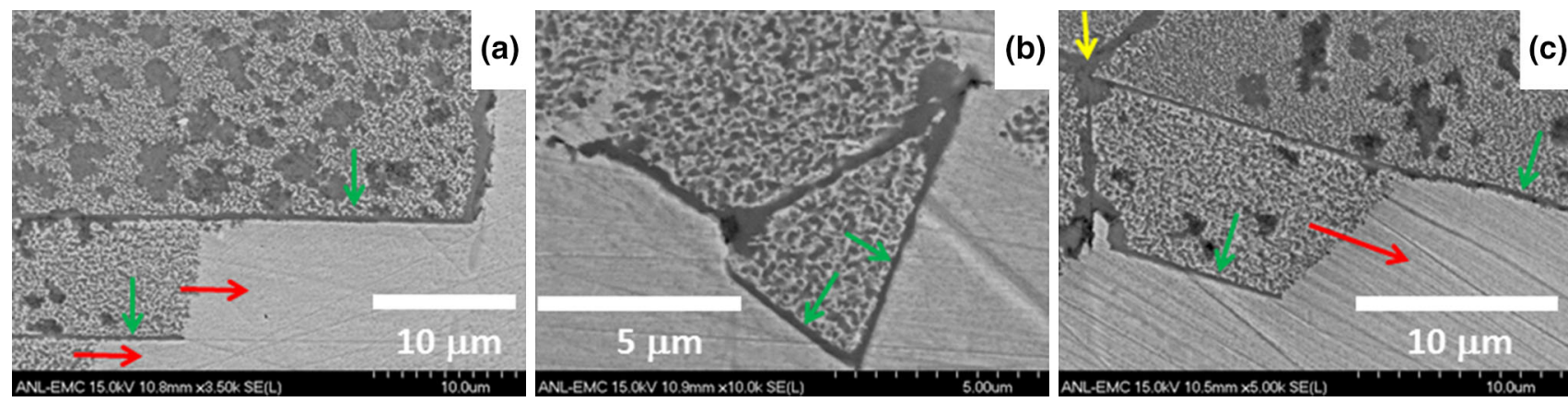

Fig. 13 SEM images of breakaway region of 321 ss after 284-h exposure to pure $\mathrm{CO}_{2}$ at $750{ }^{\circ} \mathrm{C}$. (a) Green arrows indicate that oxidation was terminated at grain boundaries. Red arrows indicate that oxidation continued to propagate. (b) Oxidation was terminated at grain boundary. (c) Oxidation was terminated at grain boundary, and then restarted at the edge of another grain (indicated by yellow arrow) (Color figure online)

oxidation is slower in $3.97 \% \mathrm{O}_{2}-96.03 \% \mathrm{CO}_{2}$ than in $0.1 \% \mathrm{O}_{2}$ $99.9 \% \mathrm{CO}_{2}$. Breakaway oxidation has not occurred on the same alloy within $320 \mathrm{~h}$, when the alloy was exposed to $21 \% \mathrm{O}_{2}$ $79 \% \mathrm{CO}_{2}$ with higher $p_{\mathrm{O}_{2}}$ than that in pure $\mathrm{CO}_{2}$. The proposed MNAO mechanism can explain why the oxide scales are easy to break away at low $p_{\mathrm{O}_{2}}$ environment.

Since $\mathrm{Cr}$ is a strongly reducing element, the oxygen partial pressure at the alloy-oxide boundary is very low. If $a_{\mathrm{Cr}}$ is assumed to be 0.183 (the mole fraction of $\mathrm{Cr}$ of 321 ss with 17.3 wt. $\% \mathrm{Cr}$ ), the calculated $p_{\mathrm{O}_{2}}$ at the alloy-oxide boundary from Eq 8 is $7.9 \times 10^{-30}$ atm at $750{ }^{\circ} \mathrm{C}$. The oxygen partial pressures of $\mathrm{CO}_{2}$ is $\approx 10^{-6}$ in the system $\left(1 \mathrm{ppm} \mathrm{O} \mathrm{O}_{2}\right.$ impurity in the $\mathrm{CO}_{2}$ gas, $1.8 \times 10^{-7}$ atm $\mathrm{O}_{2}$ at $750{ }^{\circ} \mathrm{C}$ from the equilibrium) are lower than that in $21 \% \quad \mathrm{O}_{2}-79 \% \quad \mathrm{CO}_{2}$. Therefore, the oxygen partial pressure gradient in the oxide scales for specimens exposed to $\mathrm{CO}_{2}$ or steam would be several orders of magnitude smaller than that exposed to $21 \% \mathrm{O}_{2}-79 \%$ $\mathrm{CO}_{2}$, assuming a constant oxide scale thickness. The oxygen partial pressure gradient in the oxide scales can play two roles with respect to the formation and growth of metallic nanonetworks.

First, metallic nanoparticles cannot survive in high $p_{\mathrm{O}_{2}}$ environment as iron and nickel can be oxidized. The region of the oxide scales in which $p_{\mathrm{O}_{2}}$ is low enough for the formation of these metallic nanoparticles is small at a high oxygen partial pressure gradient and little, if any, metallic nanoparticles can form. The probability of these metallic nanoparticles connecting together to form metallic nanowires is therefore also low. Second, even if a metallic nanowire has formed in an oxide scale, it cannot grow long enough at a high gradient of oxygen partial pressure. In contrast, it is possible to grow a long metallic nanowire in an environment with a low oxygen partial pressure. After long distance diffusion, the chromium concentration at the end of the metallic nanowire drops below the minimum required to form stable $\mathrm{Cr}_{2} \mathrm{O}_{3}$. $\mathrm{Cr}$ is delivered to the nonprotective spinel layer (see Fig. 12). This can be the cause of the enhanced oxidation rate seen in $\mathrm{CO}_{2}$ in which oxygen partial pressures are lower than in $21 \% \mathrm{O}_{2}-79 \% \mathrm{CO}_{2}$.

The oxide scales, in general, are mixtures of $\mathrm{Cr}_{2} \mathrm{O}_{3}$ and spinel phases. Oxygen diffuses fast in spinel but much slower in $\mathrm{Cr}_{2} \mathrm{O}_{3}$. Figure 5(e) shows the $\mathrm{Cr}_{2} \mathrm{O}_{3}$ /spinel ratio for the protective region on $321 \mathrm{ss}$. The content of $\mathrm{Cr}_{2} \mathrm{O}_{3}$ phase in the oxide scales generally increases with the decreasing distance from the alloy-oxide boundary. It is reasonable to assume that the scale is protective only if the $\mathrm{Cr}_{2} \mathrm{O}_{3}$ contents are larger than a critical value $C_{\mathrm{Cr}_{2} \mathrm{O}_{3}}$. Higher than this this value, spinel 
particles are isolated, and the contact of spinel particles is totally blocked by $\mathrm{Cr}_{2} \mathrm{O}_{3}$, so that the fast oxygen diffusion path is blocked. We define this layer with $\mathrm{Cr}_{2} \mathrm{O}_{3}$ contents $>C_{\mathrm{p}}$ as the protective layer. The oxygen activity in the mixture will be a function of external $p_{\mathrm{O}_{2}}$. If the external $p_{\mathrm{O}_{2}}$ is large, then the oxygen partial pressure gradient is also large, which can lead to the $p_{\mathrm{O}_{2}}$ in the protective layer to be larger than that required $p_{\mathrm{O}_{2}}$ to oxidize nickel. The metallic nanonetwork cannot extend out of the protective layer. A sufficient amount of $\mathrm{Cr}$ can diffuse through the short metallic wire to form $\mathrm{Cr}_{2} \mathrm{O}_{3}$. In contrast, if the external $p_{\mathrm{O}_{2}}$ is low, then the oxygen partial pressure gradient is also low, which can cause the $p_{\mathrm{O}_{2}}$ in the protective layer to be lower than the $p_{\mathrm{O}_{2}}$ required to oxidize nickel. The metallic nanonetwork can grow long enough to extend out of the protective layer. Chromium will be continuously delivered to the nonprotective layer through the long metallic wire but cannot form $\mathrm{Cr}_{2} \mathrm{O}_{3}$ since the concentration of $\mathrm{Cr}$ is not large enough after long-distance diffusion. The outward diffused $\mathrm{Cr}$ is consumed by gradual carburization in the inner oxide layer to allow the outward diffusion process to continue. These metallic nanonetworks cannot be considered only as the results of internal oxidation. These nanonetworks in oxide layers fundamentally change the transport mechanism. $\mathrm{Cr}$, Fe, and $\mathrm{Mn}$ diffuse outward and carbon diffuse inward through the networks, while oxygen diffuses inward through the spinel phase. Since transports of both the metallic elements and oxygen occur through the fastest routes, the oxidation rate greatly increases and leads to breakaway oxidation.

Figure 13(a) shows that oxidation stopped at the grain boundary because the metallic nanonetworks could not be extended across the grain boundary. The $p_{\mathrm{O}_{2}}$ in the grain will gradually increase when oxygen continues inward diffusion through the oxides, and metals are gradually oxidized. The dark spots indicate the regions where metals were totally oxidized. The oxidation process will stop when the entire grain was oxidized. Figure 13(b) shows the termination of the MNAO. Figure 13(c) shows that the MNAO has restarted at the corner of another grain. Therefore, the MNAO is not a continuous process under microscale. It is a virus-like propagation process. The rapid oxidization starts at a weak point of an infected grain. If time is not sufficient to develop such a metallic nanonetwork structure in the next grain, then the oxidation process will be terminated. Fast inward diffusion of oxygen in a high $p_{\mathrm{O}_{2}}$ gas environment can lead to easier termination of MNAO in a high $p_{\mathrm{O}_{2}}$ gas environment than in a low $p_{\mathrm{O}_{2}}$ gas environment. This is another reason why breakaway oxidation of $321 \mathrm{ss}$ is easy to propagate in a low $p_{\mathrm{O}_{2}}$ environment.

\section{Conclusions}

The present study shows that metal nanoparticles could form in the oxide scales that develop on alloy surfaces upon exposure to elevated temperatures. Metallic nanonetworks were observed in the breakaway region. In contrast, metallic nanoparticles have not connected to metallic nanonetworks at the protective region. The phase structures at the protective region are totally different from those at the nonprotective region. $\mathrm{Cr}_{2} \mathrm{O}_{3}$ is the major phase at the protective region, but $\mathrm{Cr}_{2} \mathrm{O}_{3}$ is almost absent in the breakaway region where metallic nanoparticles exist. The oxidation rate of an alloy is much faster when these metallic nanonetworks appeared. A model is proposed to explain the accelerated/breakaway oxidation using the metallic nanonetworks.

Metallic nanonetworks can act as important channels in the mass transport during the oxidation process. In contrast to diffusion of charged species such as cations, anions, and electrons as the only avenue for transport in the oxide scales, neutral metal atoms can transport through the metallic nanonetworks when these nanonetworks exist in the oxide layers. The change of the diffusion mechanism dramatically affects the solid reactions at the important reaction front at the alloy-oxide boundary. More iron atoms can be released into the oxides though the fast diffusion tunnels of metallic nanonetworks. Meanwhile, chromium is also diluted after diffusing out through metallic nanonetworks. This process results in more spinel phase and less $\mathrm{Cr}_{2} \mathrm{O}_{3}$ in the oxide layer on the alloy surface. A dense protective $\mathrm{Cr}_{2} \mathrm{O}_{3}$ does not form and, as a consequence, leads to rapid breakaway oxidation. MNAO is a type of rapid oxidation. Virus-like propagation of MNAO from grain to grain was observed. To minimize rapid MNAO, alloys should not contain elements that can lead to the formation of highly stable spinel phases in the oxide scales, which would lead to the formation of an oxide layer without $\mathrm{Cr}_{2} \mathrm{O}_{3}$.

\section{Acknowledgments}

The authors thank D. L. Rink for conducting the oxidation experiments, and Jianguo Wen for consultation on EELS analysis of iron. This study is supported by the U.S. Department of Energy, Office of Fossil Energy, Advanced Research Materials Program. The authors gratefully acknowledge the use of these following U.S. Department of Energy Office of Science User Facilities: the Advanced Photon Source, the Center for Nanoscale Materials; and the Electron Microscopy Center at Argonne National Laboratory, a U.S. Department of Energy Office of Science Laboratory operated under Contract No. DE-AC02-06CH11357 by UChicago Argonne, LLC.

\section{References}

1. G. Cao, V. Firouzdor, K. Sridharan, M. Anderson, and T.R. Allen, Corrosion of Austenitic Alloys in High Temperature Supercritical Carbon Dioxide, Corros. Sci., 2012, 60, p 246-255

2. N.J. Simms, J. Sumner, T. Hussain, and J.E. Oakey, Fireside Issues in Advanced Power Generation Systems, Mater. Sci. Technol., 2013, 29, p 804-812

3. S.K. Varma, Refractory Metals-An Exploration of High-Temperature Materials, JOM, 2010, 62, p 12

4. B. Bordenet, Influence of Novel Cycle Concepts on the HighTemperature Corrosion of Power Plants, Mater. Corros., 2008, 59, p 361-366

5. C. Wagner, Theory of the Tarnishing Process, Z. Phys. Chem. B., 1933, 21, p 25-41

6. Z. Zeng, K. Natesan, Z. Cai, and S.B. Darling, The Role of Metal Nanoparticles and Nanonetworks in Alloy Degradation, Nat. Mater, 2008, 7, p 641-646

7. E. Essuman, G.H. Meier, J. Zurek, M. Hansel, L. Singheiser, and W.J. Quadakkers, Enhanced Internal Oxidation as Trigger for Breakaway Oxidation of Fe-Cr Alloys in Gases Containing Water Vapor, Scr. Mater., 2007, 57, p 845-848

8. N.K. Othman, J. Zhang, and D.J. Yong, Water Vapor Effects on Fe-Cr Alloy Oxidation, Oxid. Met., 2010, 73, p 337-352

9. E. Sommer, S.G. Terry, W. Sigle, C. Mennicke, T. Gemming, G.H. Meier, C.G. Levi, and M. Rühle, Metallic Precipitate Formation During Alumina Growth in a FeCrAl-Based Thermal Barrier Coating Model System, Mater. Sci. Forum, 2001, 369-372, p 671-678 
10. Z. Zeng, M. Greenblatt, M.A. Subramanian, and M. Croft, Large LowField Magnetoresistance in $\mathrm{CaCu}_{3} \mathrm{Mn}_{4} \mathrm{O}_{12}$ Without Double Exchange, Phys. Rev. Lett., 1999, 82, p 3163-3167

11. P.E. Petita, F. Fargesb, M. Wilkeb, and V.A. Solé, Determination of the Iron Oxidation State in Earth Materials Using XANES Pre-Edge Information, J. Synchrotron Radiat., 2001, 8, p 952-954

12. R.D. Leapman, L.A. Grunes, and P.L. Fejes, Study of the L23 Edges in the 3D Transition-Metals and Their Oxides by Electron-Energy-Loss Spectroscopy with Comparisons to Theory, Phys. Rev. B, 1982, 26, p 614-635

13. R.L. Farrow, R.E. Benner, A.S. Nagelberg, and P.L. Mattern, Characterization of Surface Oxides by Raman-Spectroscopy, Thin Solid Films, 1980, 73, p 353-358

14. R.J. Thibeau, C.W. Brown, and R.H. Heidersbach, Raman Spectra of Possible Corrosion Products of Iron, Appl. Spectrosc., 1978, 32, p 532535

15. A.N. Hansson, H. Danielsen, F.B. Grumsen, and M. Montgomery, Microstructural Investigation of the Oxide Formed on TP 347HFG During Long-Term Steam Oxidation, Mater. Corros., 2010, 61, p 657-665

16. F. Muller and O.J. Kleppa, Thermodynamics of Formation of Chromite Spinels, J. Inorg. Nucl. Chem., 1973, 35, p 2673-2678

17. I.-H. Jung, Critical Evaluation and Thermodynamic Modeling of the Mn-Cr-O System for the Oxidation of SOFC Interconnect, Solid State Ionics, 2006, 177, p 765-777

18. J. Gilewicz-Wolter, Z. Zurek, J. Dudala, J. Lis, M. Homa, and M. Wolter, Diffusion of chromium, Manganese, and Iron in $\mathrm{MnCr}_{2} \mathrm{O}_{4}$ Spinel, J. Phase Equilib. Diffus., 2005, 26, p 561-564

19. S.P. Zholobov and M.D. Malev, The Diffusion of Oxygen in Metals on Electron Bombardment of the Surface, Zh. Tekh. Fiz., 1971, 41, p 627635

20. H.E. McCoy, Type 304 Stainless Steel vs Flowing $\mathrm{CO}_{2}$ at Atmospheric Pressure and 1100-1800F. Corrosion 1965, 21, p 84-94

21. I. Wolf and H.J. Grabke, A Study on the Solubility and Distribution of Carbon in Oxides, Solid State Commun., 1985, 54, p 5-10

22. C. Pettersson, T. Jonsson, C. Proff, M. Halvarsson, J.-E. Svensson, and L.G. Johansson, High Temperature Oxidation of the Austenitic (35Fe27Cr31Ni) Alloy Sanicro 28 in $\mathrm{O}_{2}+\mathrm{H}_{2} \mathrm{O}$ Environment, Oxid. Met., 2010, 74, p 93-111

23. H. Asteman, J.E. Svensson, L.G. Johansson, and M. Norell, Influence of Water Vapor and Flow Rate on the High-Temperature Oxidation of 304L; Effect of Chromium Oxide Hydroxide Evaporation, Oxid. Met., 2000, 54, p 11-26

24. J. Shen, L. Zhou, and T. Li, High-Temperature Oxidation of $\mathrm{Fe}-\mathrm{Cr}$ Alloys in Wet Oxygen, Oxid. Met., 1997, 48, p 347-356

25. D.J. Young, High Temperature Oxidation and Corrosion of Metals, Elsevier, Amsterdam, 2008

26. C. Wagner, Z. Elektrochem., 1959, 63, p 772-782

27. S. Wood, D. Adamonis, A. Guha, W.A. Soffa, and G.H. Meier, Internal Oxidation of Dilute Cu-Ti Alloys, Met. Trans., 1975, 6A, p 1780-1793

28. J. Megusar and G.H. Meier, Internal Oxidation of Dilute Co-Ti Alloys, Met. Trans., 1975, 7A, p 1133-1140

29. J. Kapteijn, S.A. Couperus, and J.L. Meijering, High-Temperature Oxidation of Copper with up to 4.1 wt.\% Si, Acta Metall., 1969, 17, p 1311-1315

30. P. Bolsaitis and M. Kahlweit, The Internal Oxidation of Cu-Si Alloys, Acta Metall., 1967, 15, p 765-772

31. A. Atkinson, A Theoretical Analysis of the Oxidation of Fe-Si Alloys, Corros. Sci., 1982, 22, p 87-102

32. D.L. Douglass, A Critique of Internal oxidation in Alloys During the Post-Wagner Era, Oxid. Met., 1995, 44, p 81-111

33. G.R. Laflamme and J.E. Morral, Limiting Cases of Subscale Formation, Acta Metall., 1978, 26, p 1791-1794

34. J.L. Meijering, Internal Oxidation in Alloys, Advances in Materials Research, Vol 5, H. Herman, Ed., Wiley-Interscience, New York, 1971 p $1-81$

35. R.A. Rapp, Kinetics, Microstructures and Mechanism of Internal Oxidation-Its Effect and Prevention in High Temperature Alloy Oxidation, Corrosion, 1965, 21, p 382
36. R.A. Rapp, The Transition from Internal to External Oxidation and the Formation of Interruption Bands in Silver-Indium Alloys, Acta Metall., 1961, 9, p 730-741

37. F. Gesmundo and F. Viani, Transition from Internal to External Oxidation for Binary Alloys in the Presence of an Outer Scale, Oxid. Met., 1986, 25, p 269

38. J.L. Meijering, On the Diffusion of Oxygen Through Solid Iron, Acta Metall., 1955, 3, p 157-162

39. E. Essuman, G.H. Meier, J. Zurek, L. Hansel, and W.J. Quadakkers, The Effect of Water Vapor on Selective Oxidation of Fe-Cr Alloys, Oxid. Met., 2008, 69, p 143

40. A.S. Khanna, Introduction to High Temperature Oxidation and Corrosion, Materials Park, OH, ASM International, 2002, p 118

41. J. Zurek, D.J. Young, E. Essuman, G.H. Meier, M. Hansel, H.J. Penkalla, L. Niewolak, and W.J. Quadakkers, Growth and Adherence of Chromia Based Surface Scales on Ni-Base Alloys in High- and Low-pO(2) Gases, Mater. Sci. Eng. A, 2008, 477, p 259-270

42. E. Essuman, G.H. Meier, J. Zurek, M. Hansel, L. Singheiser, and W.J. Quadakkers, Enhanced Internal Oxidation as Trigger for Breakaway Oxidation of Fe-Cr Alloys in Gases Containing Water Vapor, Scr. Mater., 2007, 57, p 845-848

43. N.K. Othman, J. Zhang, and D.J. Yong, Water Vapor Effects on Fe-Cr Alloy Oxidation, Oxid. Met., 2010, 73, p 337-352

44. A.N. Hansson, H. Danielsen, F.B. Grumsen, and M.A.J. Somers, Microstructure Evolution During Steam Oxidation of a Nb Stabilized Austenitic Stainless Steel, Oxid. Met., 2010, 73, p 289-309

45. G.H. Meier, K. Jung, N. Ma, N.M. Yanar, F.S. Pettit, J.P. Abellan, T. Olszewski, L.N. Hierro, W.J. Quadakkers, and G.R. Holcomb, Effect of Alloy Compositions on the Selective Oxidation Behavior of Ferritic Fe-Cr and Fe0Cr-X Alloys, Oxid. Met., 2010, 74, p 319-340

46. J. Askill, Tracer Diffusion Data for Metals, Alloys, and Simple Oxides, IFI/Plenum Data Corporation, New York, 1970, p 48

47. J. Kucera and K. Stransky, Diffusion in Iron, Iron Solid-Solution and Steel, Mater. Sci. Eng., 1982, 52, p 1-38

48. J. Takada, S. Yamamoto, and M. Adachi, Diffusion-Coefficient of Oxygen in Alpha-Iron Determined by Internal Oxidation Technique, $Z$. Metallkd., 1986, 77, p 6-11

49. J.H. Swisher and E.T. Turdogan, Solubility, Permeability and Diffusivity of Oxygen in Solid Iron, Trans. Met. Soc. AIME, 1967, 239, p 426-431

50. J. Takada, S. Yamamoto, S. Kikuchi, and M. Adachi, Determination of Diffusion Coefficient of Oxygen in $\gamma$-Iron from Measurements of Internal Oxidation in Fe-Al Alloys, Met. Trans., 1986, A17, p 221-229

51. J.W. Park and C.J. Altstetter, The Diffusion and Solubility of Oxygen in Solid Nickel, Met. Trans., 1987, A18, p 43-50

52. S.P. Murarka, M.S. Anand, and R.P. Agarwala, Diffusion of Chromium in Nickel, J. Appl. Phys., 1964, 35, p 1339-1341

53. A.C.S. Sabioni, B. Lesage, A.M. Huntz, J.C. Pivin, and C. Monty, SelfDiffusion in $\mathrm{Cr}_{2} \mathrm{O}_{3}$. 1. Chromium Diffusion in Single-Crystals, Philos. Mag. A, 1992, 66, p 333-350

54. A.C.S. Sabioni, A.M. Huntz, F. Silva, and F. Jomard, Diffusion of Iron in $\mathrm{Cr}_{2} \mathrm{O}_{3}$ : Polycrystals and Thin Films, Mater. Sci. Eng. A, 2005, 392, p 254-261

55. W.C. Hagel, Anion Diffusion in $\alpha-\mathrm{Cr}_{2} \mathrm{O}_{3}, J$. Am. Cer. Soc., 1965, 48, p 70-75

56. R. Hempelmann and C.H. Karmonik, Proton Diffusion in Proton Conducting Oxides, Phase Trans., 1996, 58, p 175-184

57. T. Horita, K. Yamaji, Y.P. Xiong, H. Kishimoto, N. Sakai, and H. Yokokawa, Oxide Scale Formation of Fe-Cr Alloys and Oxygen Diffusion in the Scale, Solid State Ionics, 2004, 175, p 157-163

58. R. Sun, Diffusion of Cobalt and Chromium in Chromite Spine, $J$. Chem. Phys., 1958, 28, p 290-293

59. R. Lindner and A. Akerstrom, Z. Phys. Chem., 1956, 6, p 162-177

60. A.C.S. Sabioni, R.P.B. Ramos, V. Ji, F. Jomard, W.A.D. Macedo, P.L. Gastelois, and V.B. Trindade, About the Role of Chromium and Oxygen Ion Diffusion on the Growth Mechanism of Oxidation Films of the AISI, 304 Austenitic Stainless Steel, Oxid. Met., 2012, 78, p 211220 